$5-16-2003$

\title{
Evaluating The Effects of Enhanced Processivity and Metal Ions on Translesion DNA Replication Catalyzed by The Bacteriophage T4 DNA Polymerase
}

\author{
Edmunds Z. Reineks \\ Case Western Reserve University \\ Anthony J. Berdis \\ Cleveland State University, A.BERDIS@csuohio.edu
}

Follow this and additional works at: https://engagedscholarship.csuohio.edu/scichem_facpub

Part of the Biochemistry Commons, and the Chemistry Commons

How does access to this work benefit you? Let us know!

\section{Recommended Citation}

Reineks, Edmunds Z. and Berdis, Anthony J., "Evaluating The Effects of Enhanced Processivity and Metal Ions on Translesion DNA Replication Catalyzed by The Bacteriophage T4 DNA Polymerase" (2003). Chemistry Faculty Publications. 191.

https://engagedscholarship.csuohio.edu/scichem_facpub/191 


\title{
Evaluating the Effects of Enhanced Processivity and Metal Ions on Translesion DNA Replication Catalyzed by the Bacteriophage T4 DNA Polymerase
}

\author{
Edmunds Z. Reineks and Anthony J. Berdis
}

\begin{abstract}
The fidelity of DNA replication is achieved in a multiplicative process encompassing nucleobase selection and insertion, removal of misinserted nucleotides by exonuclease activity, and enzyme dissociation from primer/templates that are misaligned due to mispairing. In this study, we have evaluated the effect of altering these kinetic processes on the dynamics of translesion DNA replication using the bacteriophage T4 replication apparatus as a model system. The effect of enhancing the processivity of the T4 DNA polymerase, gp43, on translesion DNA replication was evaluated using a defined in vitro assay system. While the T4 replicase (gp43 in complex with gp45) can perform efficient, processive replication using unmodified DNA, the T4 replicase cannot extend beyond an abasic site. This indicates that enhancing the processivity of gp43 does not increase unambiguously its ability to perform translesion DNA replication. Surprisingly, the replicase composed of an exonucleasedeficient mutant of gp43 was unable to extend beyond the abasic DNA lesion, thus indicating that molecular processes involved in DNA polymerization activity play the predominant role in preventing extension beyond the non-coding DNA lesion. Although neither T4 replicase complex could extend beyond the lesion, there were measurable differences in the stability of each complex at the DNA lesion. Specifically, the exonuclease-deficient replicase dissociates at a rate constant, $k_{\text {off }}$, of $1.1 \mathrm{~s}^{1}$ while the wild-type replicase remains more stably associated at the site of DNA damage by virtue of a slower measured rate constant ( $k_{\text {off }}$ $\left.0.009 \mathrm{~s}^{1}\right)$. The increased lifetime of the wild-type replicase suggests that idle turnover, the partitioning of the replicase from its polymerase to its exonuclease active site, may play an important role in maintaining fidelity. Further attempts to perturb the fidelity of the T4 replicase by substituting $\mathrm{Mn}^{2+}$ for $\mathrm{Mg}^{2+}$ did not significantly enhance DNA synthesis beyond the abasic DNA lesion. The results of these studies are interpreted with respect to current structural information of gp43 alone and complexed with gp45.
\end{abstract}

\section{Introduction}

The fidelity of DNA replication as well as its coordination with other cellular processes is essential for the survival and proliferation of any organism. Mutagenesis caused by improper DNA replication can lead to a variety of cellular defects including cancer ${ }^{1-3}$ or the development of drug resistance in bacterial and viral pathogens. ${ }^{4-6}$ While defects in DNA replication are historically associated with disease development, certain mutagenic events may be beneficial to an organism 
or species. For example, mutagenic or "errorprone" DNA replication is a key event in evolution $^{7}$ as well as in the generation of immunological diversity in humans. ${ }^{8,9}$ Despite the important ramifications of mutagenesis, the molecular mechanisms governing precise versus mutagenic DNA synthesis have yet to be delineated fully.

Here, we have evaluated the dynamics of translesion DNA replication quantitatively using the bacteriophage $\mathrm{T} 4$ replication apparatus as a model system and employing the abasic site as the prototypical, non-coding DNA lesion. Although considered to be a simple replication system, the bacteriophage T4 replicative proteins share functional homology with those present in higher eukaryotic systems. ${ }^{10}$ These similarities provide a useful paradigm toward deciphering how the various protein components "communicate" with each other during precise and translesion DNA synthesis. Both bacteriophage T4 and eukaryotes utilize three core proteins in the formation and propagation of the leading strand replication fork. ${ }^{11,12}$ In bacteriophage T4, these proteins include the T4 DNA polymerase (gp43), the central component of the T4 replicase, as well as two accessory proteins, gp45 and gp44/62, which act as the "clamp"13,14 and "clamp loader"1,13, respectively. gp43 catalyzes the incorporation of nucleotides in the $5^{\prime}$ to $3^{\prime}$ direction and maintains fidelity through the assistance of its intrinsic $3^{\prime}$ to $5^{\prime}$ exonuclease activity. ${ }^{15}$ The association of the accessory proteins with the DNA polymerase decreases the rate at which the polymerase dissociates from DNA, and thus enhances the intrinsically low processivity of gp43. ${ }^{16-18}$ For example, gp43 dissociates from DNA at a rate constant $\left(k_{\text {off }}\right)$ of $\sim 2 \mathrm{~s}{ }^{1} \cdot{ }^{15,19,20}$ However, when complexed with gp45, gp43 dissociates from DNA with a $k_{\text {off }}$ value of $0.01 \mathrm{~s}^{1}{ }^{17,20,21}$ The change in dissociation kinetics represents the ability of gp45 to "tether" the polymerase to DNA and corresponds to a 200-fold increase in processivity of the T4 replicase (gp43 complexed with gp45) compared to gp43 alone. Although increasing the processivity of most polymerases is essential for efficient leading-strand DNA synthesis, the potential role by which it may enhance mutagenesis is poorly defined. It is easy to envision that decreasing the rate of polymerase dissociation if it encounters a DNA lesion may actually favor replication opposite and/or beyond the lesion. Using the T4 system as an example, the slow dissociation rate constant of $0.01 \mathrm{~s}^{1}$ of the $\mathrm{T} 4$ replicase could actually enhance extension beyond DNA damage if the rate of nucleotide insertion is faster than the rate of dissociation. Indeed, the rate constants of $0.15 \mathrm{~s}^{1}$ and $\sim 0.2 \mathrm{~s}^{1}$ for insertion opposite and beyond the lesion, respectively, predict that this is the case.

gp43 normally displays an extraordinary high degree of fidelity ${ }^{22}$ and this property provides a useful tool toward studying how various DNA lesions affect the fidelity and efficiency of DNA synthesis. Using unmodified DNA, the remarkably low error rate of only one dNMP misincorporation per $10^{8}$ turnovers results from a number of mechanisms (outlined in Schemes 1 and 2) that collectively contribute to either preventing a misinsertion event or correcting it should such a misinsertion event occur. Arguably the most important kinetic step in maintaining fidelity is the DNA polymerization step (Scheme 1, step A). This macroscopic step is composed of several microscopic kinetic events (depicted in Scheme 2), each of which contributes with varying degrees toward catalysis and fidelity. First amongst these steps is the binding of dNTP to the polymerase: nucleic acid complex. Proper dNTP binding has been attributed historically to the formation of Watson-Crick base-pairs between the incoming dNTP and template nucleobase (Scheme 2, step 1). ${ }^{23,24}$ Upon binding of the correct dNTP, the polymerase:DNA complex undergoes a conformational change (Scheme 2, step 2) to further align the incoming dNTP into the correct geometric arrangement for phosphoryl transfer (Scheme 2, step 3). These microscopic events provide an error frequency of one misincorporation event per $10^{5}-10^{6}$ turnovers $^{24}$ and collectively account for the induced-fit mechanism of fidelity. ${ }^{23}$ In this mechanism, potential misinsertion intermediates are actively discriminated against by virtue of improper binding, inappropriate orientation, and/ or diminished rate of phosphoryl transfer.

If the polymerase does misincorporate,

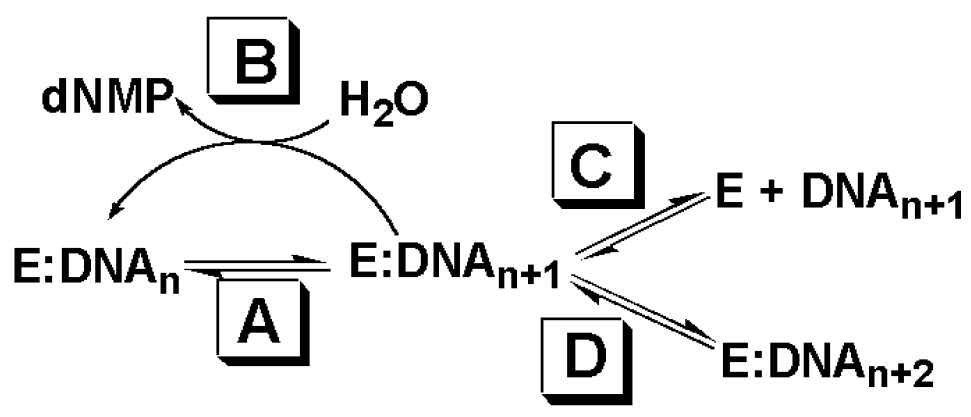

Scheme 1. Macroscopic kinetic steps associated with the maintenance of fidelity. Step A encompasses kinetic steps including dNTP binding, conformational changes prior to and after phosphoryl transfer, phosphoryl transfer itself, and pyrophosphorolysis, the reversal of DNA polymerization. Step B represents the exonucleolytic degradation of the mispaired primer/ template, $\mathrm{DNA}_{n+1}$, to yield $\mathrm{DNA}_{n}$. Step C reflects polymerase dissociation from the mispaired DNA substrate. Step D represents DNA polymerization toward extending the mispaired primer/template, $\mathrm{DNA}_{n+1}$, to generate $\mathrm{DNA}_{n+2}$. 


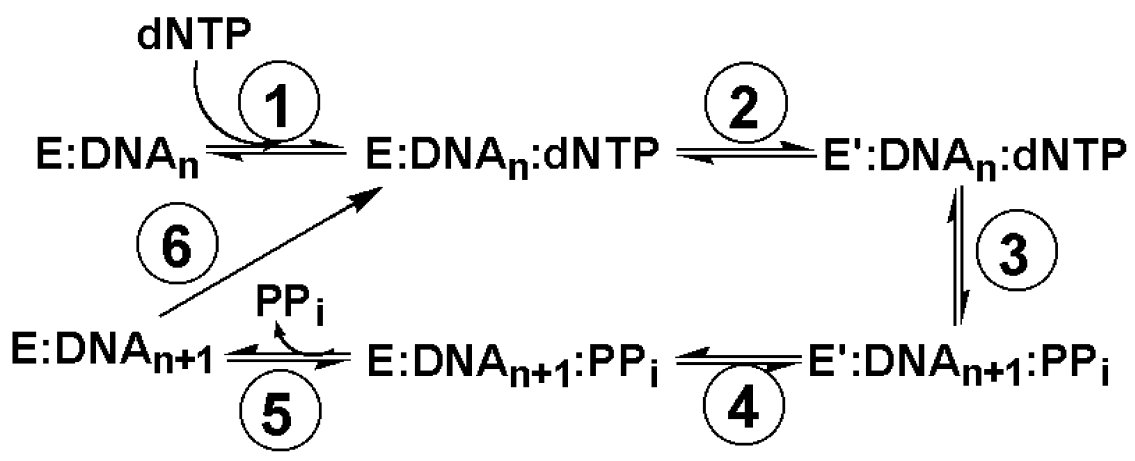

Scheme 2. Minimal kinetic mechanism for the polymerization activity of gp43, the bacteriophage T4 DNA polymerase. Step 1 represents dNTP binding to the polymerase:nucleic acid complex. Step 2 represents the conformational change prior to phosphoryl transfer. Step 3 represents phosphoryl transfer. Step 4 represents the conformational change after phosphoryl transfer. Step 5 represents the release of the first product, pyrophosphate. Step 6 collectively represents translocation of gp43 to the next insertion position and binding of the next correct dNTP. E, gp43; DNA ${ }_{n}$, DNA substrate; $\mathrm{E}^{\prime}$, conformational change in DNA polymerase; $\mathrm{PP}_{\mathrm{i}}$, inorganic pyrophosphate; $\mathrm{DNA}_{n+1}$, DNA product (DNA extended by one nucleobase).

additional macroscopic steps illustrated in Scheme 1 must play a significant role in reducing the error frequency an additional 1000-fold. The predominant step has been attributed to proofreading through the associated exonuclease activity of gp43 (Scheme 1, step B). In addition to excising the misinserted dNMP, proofreading returns the polymerase to a correct primer/template junction, which allows the enzyme to renew "correct" DNA synthesis without an obligatory enzyme dissociation step. Thus, the coordinated efforts of polymerization and exonuclease proofreading provide the T4 replicase with the means to maintain fidelity without compromising the continuity of DNA replication.

The third macroscopic step that contributes to genomic fidelity is polymerase dissociation from the DNA prior to or after the misinsertion event (Scheme 1, step C). Due to the altered geometry of the formed mispair, ${ }^{25}$ the rate constant at which the polymerase dissociates from the mispaired primer/template may be enhanced. However, during in vivo replication, the DNA polymerase will be complexed with its accessory proteins, ${ }^{13,14}$ so that its ability to dissociate from the primer/ template is reduced. ${ }^{16-18}$ The associated enhancement in the processivity may actually favor the ability of the polymerase to extend beyond a mispaired primer/template (Scheme 1, step D). In the case of bacteriophage T4, this mechanism is conceivable, since the interaction of gp45 with gp43 reduces the rate of polymerase dissociation from $2 \mathrm{~s}^{115,19,20}$ to $0.01 \mathrm{~s} 117,20,21$ and provides ample time for extension beyond a misinsertion event to propagate the genomic error. Indeed, Fijalkowski et al. demonstrated through in vivo techniques that replication on the lagging strand has a higher degree of fidelity as compared to that on the leading strand in Escherichia coli. ${ }^{26}$ These results suggested that differences in replication fidelity could reflect the inherently faster dissociation rate of the lagging strand replicase as compared to the more stable and processive leading-strand complex.

To examine this potential mechanism, we evaluated if enhancing the processivity of gp43 affects its fidelity and allows for extension beyond an abasic site DNA lesion. This research extends our previously published work demonstrating that the exonuclease-deficient form of gp43 (gp43 exo ) was able to replicate opposite and beyond this type of lesion with varying efficiencies. ${ }^{27,28}$ These studies demonstrated that dATP and dGTP are inserted preferentially opposite the abasic lesion, despite the lack of any coding information present at this lesion. ${ }^{27,28}$ While the catalytic efficiency for the insertion of dATP opposite the abasic site was reduced by only 1000-fold compared to insertion opposite $\mathrm{T}^{27}$ extension beyond the lesion was hindered severely. ${ }^{27}$ Collectively, these data suggested that extension beyond the lesion is the rate-limiting step in the propagation of a mutagenic event. We now evaluate the dynamics of the propagation step by examining if replicative accessory proteins enhance the ability of the DNA polymerase to extend this class of DNA lesion. Directly comparing the activity of the wild-type or an exonuclease-deficient DNA polymerase when complexed with its processivity factor evaluates the role that exonuclease proofreading plays in preventing translesion DNA synthesis.

\section{Results}

\section{Effect of enhanced processivity on DNA replication}

We have demonstrated that gp43 exo can extend beyond an abasic DNA lesion. ${ }^{27}$ However, the efficiency of translesion DNA replication by gp43 alone was low and is observed using short DNA substrates only if the concentration of enzyme is maintained in molar excess versus DNA substrate. Although these reaction conditions were employed to simplify subsequent kinetic analyses, the physiological significance of these results may be questioned for several reasons. With regards to reaction conditions, the concentration of DNA polymerase is typically lower than that of nucleic 


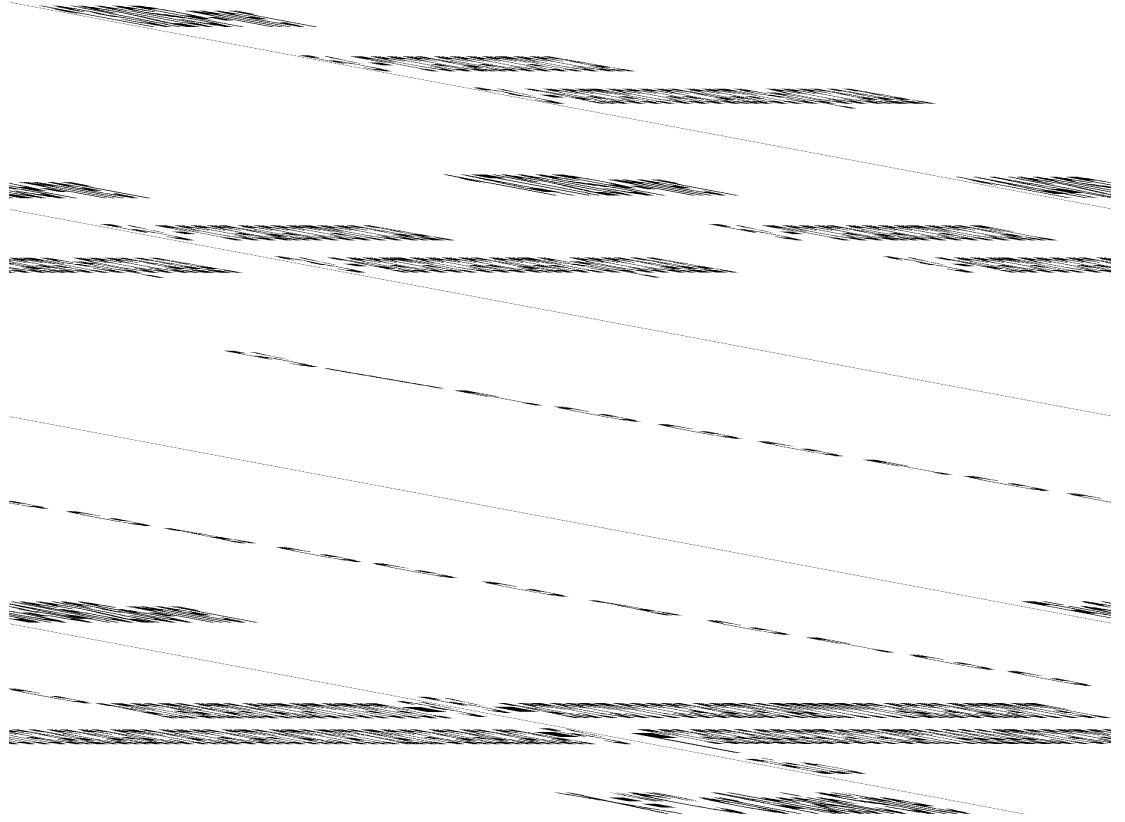

Figure 1. DNA substrates used for kinetic analysis. Sp denotes the tetrahydrofuran moiety designed to mimic an abasic site. acid substrate during in vivo DNA replication. With regards to DNA substrate, in vivo replication takes place within the confines of the replication fork. As such, gp43 interacts with larger forms of nucleic acid and must associate with a variety of replicative accessory proteins to catalyze efficient DNA synthesis. Since these parameters affect the activity of gp43 during correct DNA replication, ${ }^{16,17,20}$ we wished to evaluate if these parameters also influenced the ability of the polymerase to perform translesion DNA replication. We thus performed experiments measuring the ability of the DNA polymerase in conjunction with the replicative accessory proteins to perform translesion DNA replication using a forked DNA substrate (Figure 1) designed to mimic an in vivo replication fork.
The dynamics of precise and translesion DNA replication were compared using the defined biotinylated primer/template system previously employed to monitor processive DNA synthesis catalyzed by the T4 replicase. ${ }^{20,21,29,30}$ Subtle modifications of this DNA substrate facilitated direct comparison of data monitoring translesion DNA synthesis with that reported for "precise" DNA synthesis. ${ }^{29,30,31}$ As outlined in Scheme 3, processive DNA synthesis by the T4 replicase (gp43 in complex with gp45) using the Bio-34/62/36-mer DNA substrate (in the presence of streptavidin) results in strand displacement of the 36-mer forked strand to produce fully elongated products, i.e. 62-mer. Smaller products (<43-mers) are generated by gp43 not complexed with gp45, since the DNA
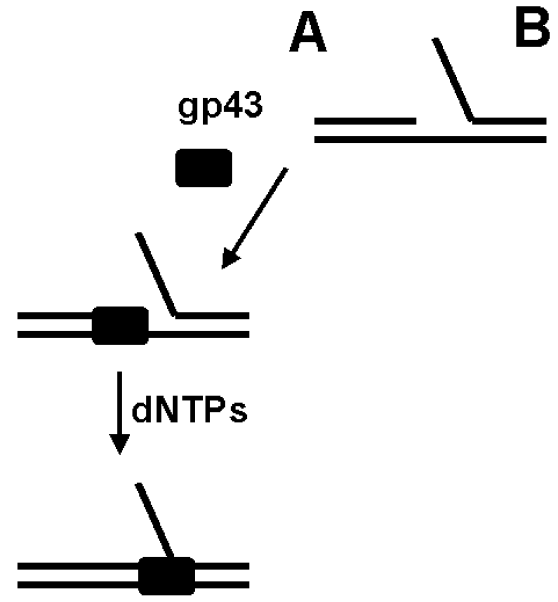
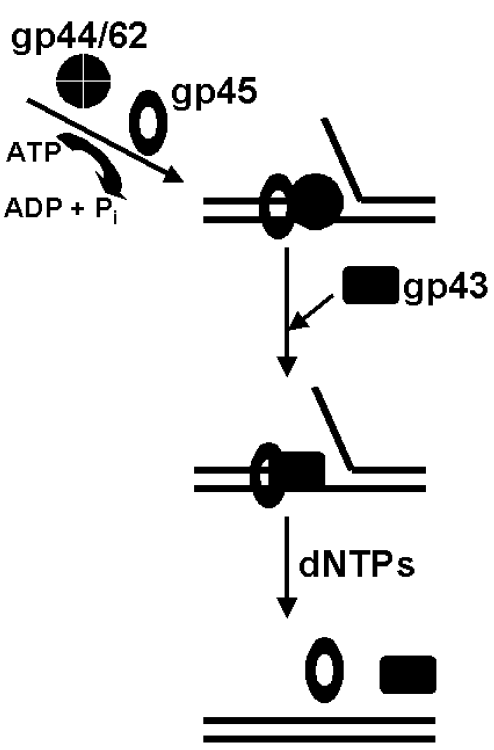

Scheme 3. A representation of the experimental paradigm designed to monitor processive DNA synthesis. (A) gp43 binds to the Bio-34/62/ 36-mer DNA substrate. In the presence of all dNTPs, the polymerase can replicate up to the forked strand. Since the polymerase cannot perform strand displacement synthesis efficiently within the reaction times employed in this study, products accumulate predominantly at position 43 (the interface between the forked 36-mer and the template Bio62-mer). (B) In the presence of ATP, gp44/62 loads gp45 onto the Bio-34/62/36-mer DNA substrate. gp43 then binds the loaded gp45 to form the $\mathrm{T} 4$ replicase. In the presence of all dNTPs, the enhancement in processivity of the polymerase imparted by gp45 allows the replicase to perform

strand displacement synthesis. Thus, 62-mer products accumulate predominantly, and these can be resolved from Bio-62-mer substrate by denaturing gel electrophoresis. 


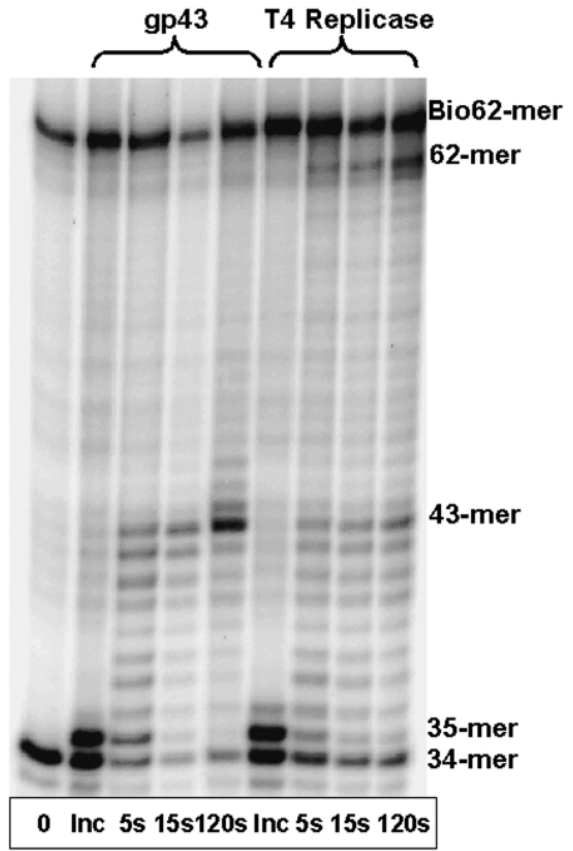

Figure 2. Processive DNA synthesis catalyzed by the bacteriophage T4 replicase as monitored by strand displacement DNA synthesis. Reaction products separated on a $16 \%$ denaturing polyacrylamide gel. Lanes demarcated as 0 depict unextended primer/template. Lane Inc represents single-nucleotide extension of the DNA substrate. In lanes denoted as gp43, $200 \mathrm{nM}$ gp43 was mixed with $500 \mathrm{nM}$ Bio-34/62/36-mer primer/template,

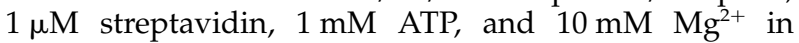
assay buffer. In lanes denoted as T4 replicase, $200 \mathrm{nM}$ gp43 exo (was mixed with $500 \mathrm{nM}$ Bio-34/62/36-mer,

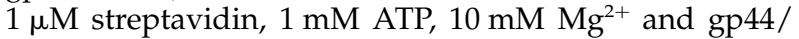
62 and gp45 (550 $\mathrm{nM}$ each). The polymerization reaction was then initiated by the addition of $100 \mu \mathrm{M}$ dCTP (the next correct dNTP) and an aliquot was quenched to provide the Inc samples. After 15 seconds, the remaining dNTPs $(100 \mu \mathrm{M}$ each) were added to initiate processive DNA replication.

polymerase alone cannot perform strand displacement synthesis efficiently within the reaction times employed in this study. The data presented in Figure 2 reveal that, by itself, wild-type gp43 is capable of nucleotide incorporation only up to the fork strand, while the wild-type T4 replicase (gp43 complexed with gp45) is capable of strand displacement synthesis to yield fully elongated primer. These experiments recapitulate previously reported results ${ }^{20,29,30}$ and confirm how gp45 enhances the dynamics of precise DNA synthesis. More importantly, these data provide a standard reflecting the efficiency and fidelity of the T4 replicase so that the effects of DNA lesions on the efficacy of polymerization activity can be compared directly and quantified.

\section{Enhanced processivity does not facilitate translesion DNA synthesis}

The ability of the wild-type $\mathrm{T} 4$ replicase to
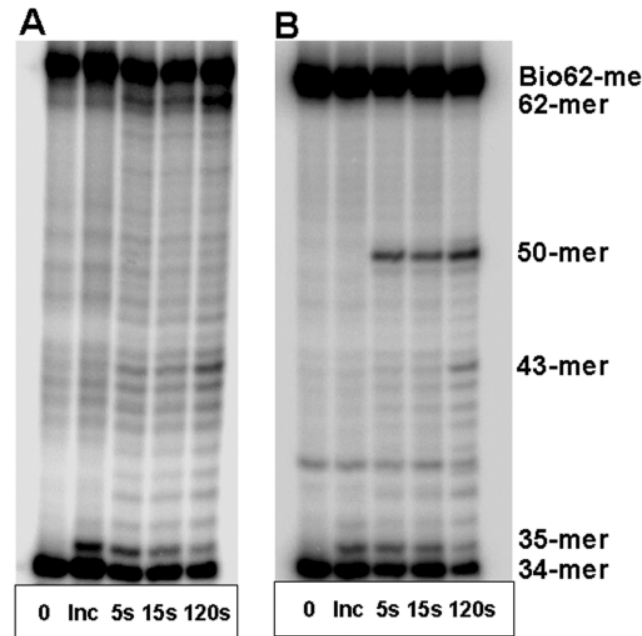

Figure 3. Direct comparison of the ability of the bacteriophage T4 replicase to perform "precise" DNA synthesis (A) versus extension beyond an abasic site DNA lesion (B). Reaction products separated on a $16 \%$ denaturing polyacrylamide gel. Lanes demarcated as 0 depict unextended primer/template only. Wild-type gp43 (200 nM) was mixed with $500 \mathrm{nM}$ Bio-34/62/36-mer (A) or $500 \mathrm{nM}$ Bio-34/62Sp/36-mer (B), gp44/62 and gp45 (550 $\mathrm{nM}$ each), $1 \mu \mathrm{M}$ streptavidin, $1 \mathrm{mM}$ ATP, and $10 \mathrm{mM} \mathrm{Mg}^{2+}$ in assay buffer. The polymerization reaction was then initiated by the addition of $100 \mu \mathrm{M}$ dCTP (the next correct dNTP) and an aliquot was quenched after ten seconds (lane Inc). The remaining dNTPs $(100 \mu \mathrm{M}$ each) were added to initiate processive DNA replication. Aliquots of each reaction were quenched at the times designated and processed as described in the text.

extend beyond an abasic site was next evaluated under identical reaction conditions using the Bio34/62SP/36-mer DNA substrate. The results provided in Figure 3 compare directly the efficiency of precise (A) versus translesion (B) DNA synthesis catalyzed by the wild-type T4 replicase. The production of 62-mer using unmodified DNA is again indicative of complete strand displacement DNA synthesis. However, a different result is obtained when the wild-type T4 replicase is challenged with extending beyond an abasic DNA lesion. Although the wild-type $\mathrm{T} 4$ replicase performs strand displacement DNA synthesis, it cannot extend beyond the lesion to generate full-length, 62 -mer product. Specifically, DNA replication is terminated at position 50, one nucleobase prior to the abasic site.

The amount of strand displacement product formed in both reactions was quantified by PhosphorImaging techniques using the 120 seconds time-point as the reference $\uparrow$. At this time-point, the concentration of full-length product (62-mer) during precise DNA replication is $150 \mathrm{nM}$, whereas

$\dagger$ The 120 seconds time-point was chosen as a convenient reference point to illustrate the ability of the T4 replicase synthesize up to the DNA lesion as well as to illustrate the renewal of DNA synthesis, which is used to demonstrate the kinetics of replicase dissociation. 

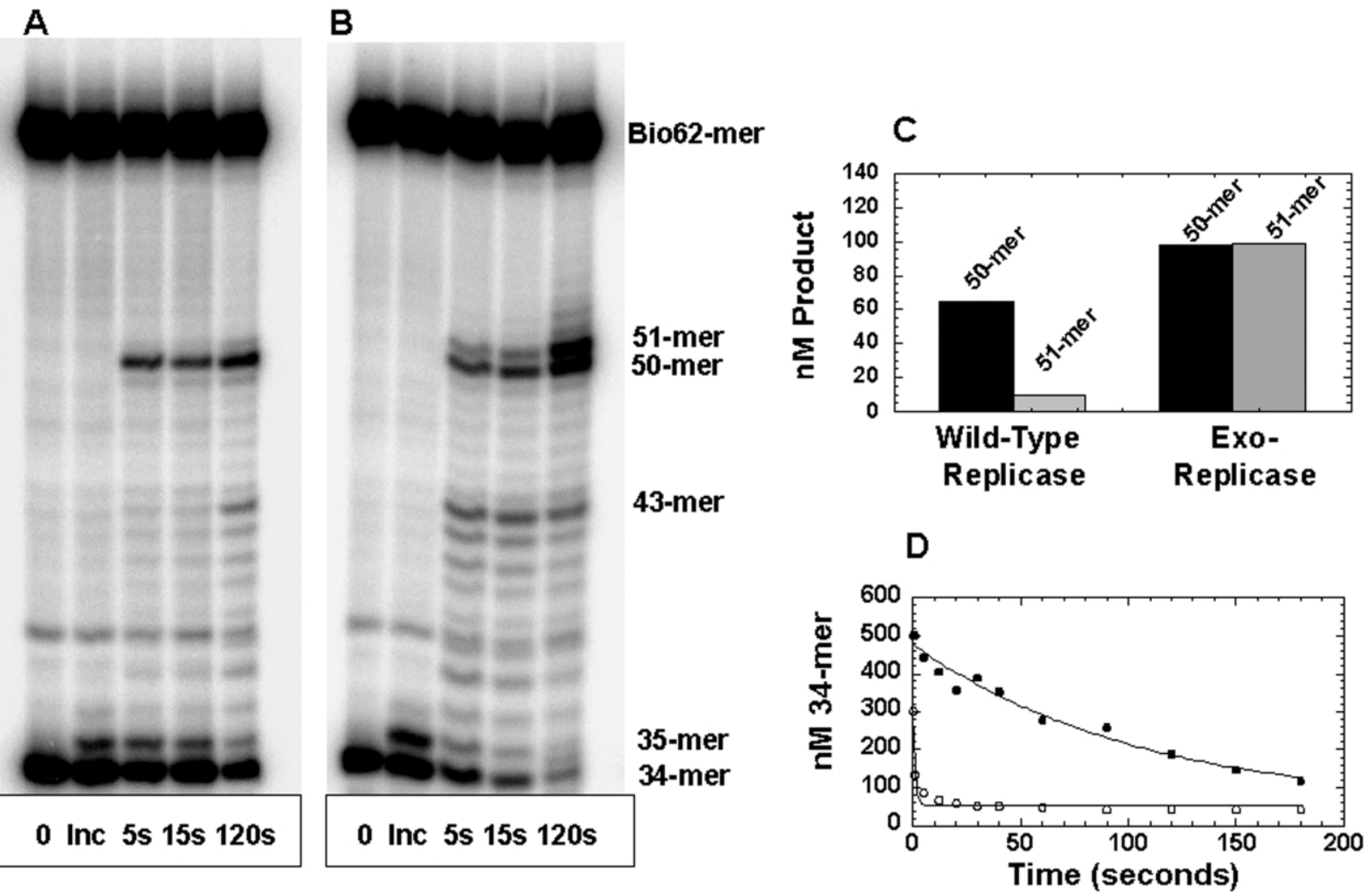

Figure 4. Elimination of exonuclease proofreading does not substantially enhance translesion DNA replication. (A) and (B) directly compare the ability of the wild-type replicase (A) or the exonuclease-deficient replicase (B) to extend beyond an abasic site DNA lesion. Reaction products separated on a denaturing $16 \%$ polyacrylamide gel. Lanes demarcated as 0 depict unextended primer/template only. $200 \mathrm{nM}$ wild-type gp43 (A) or gp43 exo (B) was mixed with $500 \mathrm{nM}$ Bio-34/62Sp/36-mer, gp44/62 and gp45 (550 nM each), $1 \mu \mathrm{M}$ streptavidin, $1 \mathrm{mM}$ ATP, and $10 \mathrm{mM} \mathrm{Mg}{ }^{2+}$ in assay buffer. The polymerization reaction was then initiated by the addition of $100 \mu \mathrm{M} \mathrm{dCTP}$ (the next correct $\mathrm{dNTP}$ ) and an aliquot was quenched after 15 seconds (lane Inc). The remaining dNTPs (100 $\mu \mathrm{M}$ each) were added to initiate processive DNA replication. Aliquots of each reaction were quenched the times designated and processed as described in the text. (C) Data obtained from PhosphorImager analysis of gel electrophoresis displaying the differences in product accumulation upon encountering an abasic site between the wild-type and exo T4 replicase. Product formation is provided for the 120 second time-points depicted in (A) and (B). (D) Data obtained from PhosphorImager analysis of gel electrophoresis displaying the depletion of 34-mer primer by the wild-type $(\bullet)$ or exo (O) T4 replicase. The depletion of 34-mer provides an indirect measure of the kinetics representing replicase dissociation from the abasic site. The faster rate of 34-mer depletion displayed by the exo T4 replicase signifies a faster rate of dissociation from the abasic site DNA lesion as compared to the wild-type replicase.

the concentration of 50-mer produced during translesion DNA replication is $120 \mathrm{nM}$. The nearly identical amount of total product formation in either case indicates that the presence of the abasic site does not affect DNA replication adversely prior to encountering the lesion. We note that the amount of strand displacement product (120$150 \mathrm{nM}$ ) is less than the concentration of wild-type gp43 used in each assay (200 nM). However, the $\sim 50 \%$ difference is consistent with previous work demonstrating that a significant fraction of gp43 can be sequestered into a non-productive complex with gp45 under the reaction conditions employed. ${ }^{20}$

\section{The lack of exonuclease proofreading does not facilitate translesion DNA synthesis}

The lack of extension beyond the abasic site indicates that increasing the processivity of gp43 does not enhance translesion DNA synthesis. Secondly, the accumulation of 50-mer product illustrated the inability of the wild-type T4 replicase to stably incorporate a dNMP opposite the lesion. Since these two results could reflect the contribution of exonucleolytic proofreading, we next set out to assess the importance of this activity toward the prevention of translesion DNA replication by using an exonuclease-deficient mutant of gp43. Representative data provided in Figure 4 compares directly the ability of the wild-type or exo T4 replicase to extend beyond the abasic site. The lack of full-length 62-mer product observed after 120 seconds indicates that neither form of the replicase can extend beyond the lesion. It is important to emphasize that extension beyond the lesion to yield fully extended primer is not observed even after a reaction time of 30 minutes (data not shown). Thus, increasing the processivity of gp43, even in the absence of exonucleolytic proofreading, 


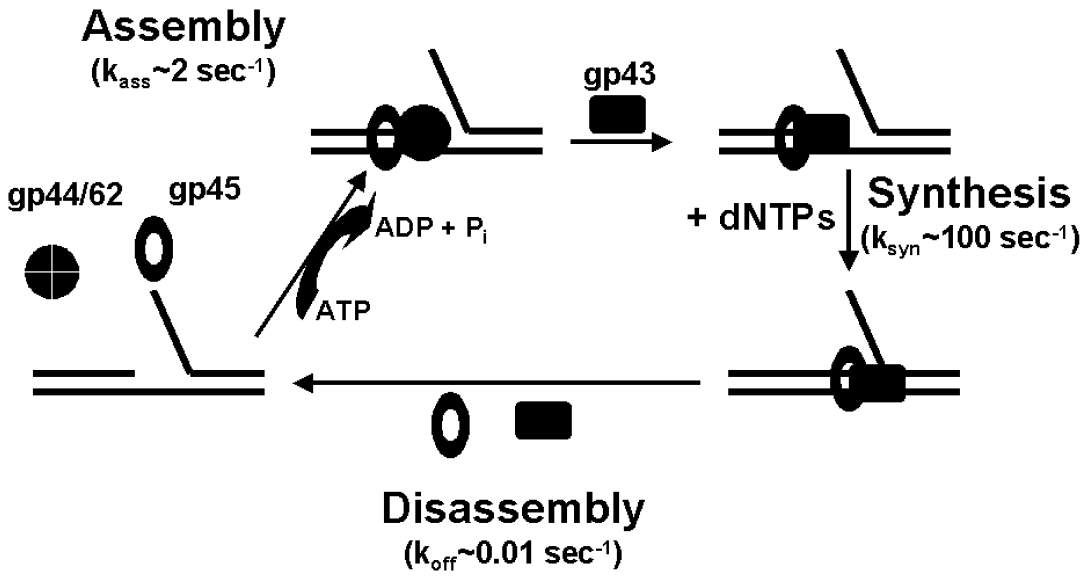

Scheme 4. A representation accounting for the renewal of DNA synthesis. Assembly of the replicase at a primer/template is an ATPdependent process $^{14,15,19}$ that proceeds with a rate constant of $\sim 2 \mathrm{~s}{ }^{1} \cdot{ }^{20,62}$ After assembly of the replicase and in the presence of the required dNTPs, DNA synthesis proceeds at a rate constant of $\sim 100 \mathrm{~s}{ }^{1} .13,27$ The rate constant for replicase decomposition monitored through "pausing" is reported as $0.01 \mathrm{~s}^{1} \cdot 17,20,21$ The slow rate constant of replicase disassembly typically makes this step rate-limiting for the renewal of DNA synthesis.

does not enhance translesion DNA replication unambiguously.

Although neither form of the T4 replicase could generate full-length product, we noticed several differences in the time-courses between the two. The first distinction is with respect to product accumulation. Specifically, the wild-type T4 replicase terminates DNA synthesis one nucleobase prior to the abasic site (position 50) whereas the exo T4 replicase terminates DNA synthesis prior to and opposite the abasic site (positions 50 and 51). The accumulation of 51-mer product with the exo T4 replicase indicates that the lack of exonuclease activity allows the DNA polymerase to insert a dNMP opposite the abasic site and is consistent with our previously published data $\dagger .{ }^{27}$ The inability of the replicase to solely generate 51-mer product, i.e. complete dNMP insertion opposite the abasic lesion, likely reflects the fact that the concentration of dNTP $(100 \mu \mathrm{M})$ used in these assays is far below saturation to maximize the rate of dNMP insertion opposite the lesion. ${ }^{27}$

The second distinction between the behavior of the wild-type and exo T4 replicase is more subtle and reflects differences in the total amount of strand displacement products formed during the course of the reaction. Despite the utilization of identical reaction conditions, visual inspection of Figure 4(A) and (B) clearly shows that a larger amount of strand displacement product is formed with the exo T4 replicase as compared to the wild-type T4 replicase. This difference was again quantified using 120 seconds as the reference time-point (Figure $4(\mathrm{C})$ ) and shows that the total amount of strand displacement products (50-mer and 51-mer) formed with the wild-type T4 replicase is $80 \mathrm{nM}$, while that formed with the exo T4 replicase is $200 \mathrm{nM}$. The 2.5 -fold increase in total product formation does not arise from differences

$\dagger$ dAMP is likely to be inserted preferentially opposite the abasic site in this instance, since the $K_{\mathrm{d}}$ value for $\mathrm{dAMP}$ insertion opposite an abasic lesion is $35 \mu \mathrm{M}$, while the $K_{\mathrm{d}}$ values for the other dNMPs are greater than $250 \mu \mathrm{M}){ }^{27}$ in gp43 concentration and/or polymerization activity $\ddagger$ Secondly, the increase in strand displacement products occurs concomitantly with the depletion of the original 34-mer substrate which, within the time-frame tested, is observed with the exo T4 replicase but not with the wild-type T4 replicase.

Since these experiments were performed in the absence of a polymerase "trap", i.e. competitor DNA, the increase in product formation reflects turnover of the $\mathrm{T} 4$ replicase required to reinitiate DNA synthesis from the 34-mer primer. The reinitiation of DNA synthesis can result only from the sequence of events encompassing dissociation of the replicase from the DNA lesion, reassembly of the replicase at another usable primer/template, and renewal of DNA synthesis (Scheme 4). Note that the rate constants of $\sim 2 \mathrm{~s}^{1}$ and $\sim 100 \mathrm{~s}^{1}$ for replicase assembly ${ }^{16,20}$ and DNA synthesis, ${ }^{15,19}$ respectively, are extremely fast compared to the $k_{\text {off }}$ of $0.01 \mathrm{~s}^{1}$ measured previously for replicase dissociation during precise DNA synthesis. ${ }^{17,20,21}$ On the basis of the dynamics of the pathway, replicase dissociation is most likely the rate-limiting step for the renewal of DNA synthesis observed in these experiments. Thus, the rate constant corresponding to replicase dissociation can be evaluated by measuring the rate constant for the depletion of the 34-mer substrate. The depletion of 34-mer substrate using either the wild-type or exo replicase was plotted as a function of time (Figure 4(D)) and the resulting time-courses are best described as single-exponential decays. Each time-course was fit to equation (1) and provided $k_{\text {off }}$ values of

$¥$ The twofold increase in strand displacement products could result from using a higher concentration of exo DNA polymerase. This possibility is unlikely, since the concentration of both the wild-type and exo DNA polymerase were determined

spectrophotometrically as well as through active-site titration of each DNA polymerase. Active-site titrations of the wild-type and exonuclease-deficient DNA polymerase are provided as Supplementary Material Figure S1. 
A

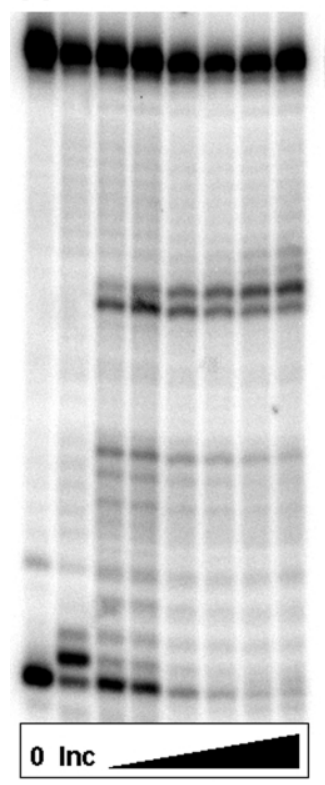

B

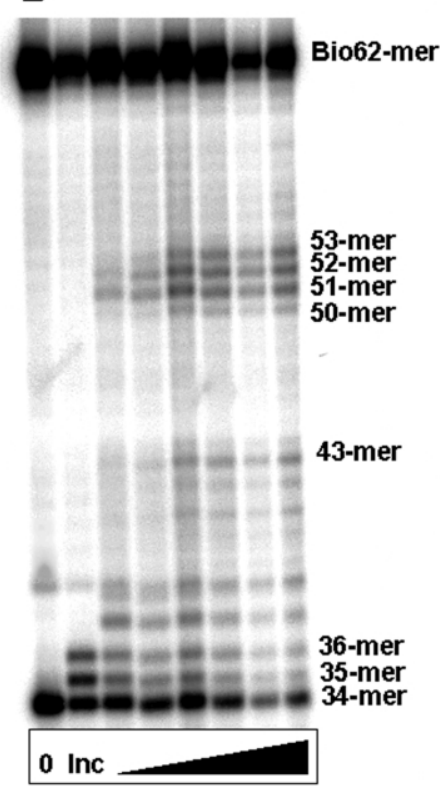

C

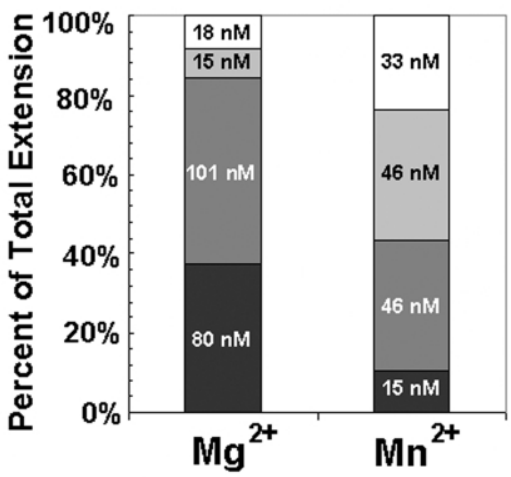

Figure 5. Altering the fidelity of DNA polymerization by substituting $\mathrm{Mn}^{2+}$ for $\mathrm{Mg}^{2+}$ does not enhance translesion DNA replication. Reaction products separated on a denaturing $16 \%$ polyacrylamide gel directly compare the ability of the exonuclease-deficient bacteriophage T4 replicase to extend beyond an abasic site DNA lesion in the presence of $\mathrm{Mg}^{2+}$ (A) or $\mathrm{Mn}^{2+}$ (B). Lanes demarcated as 0 depict unextended primer/template only. Gp43 exo (200 nM) was mixed with $500 \mathrm{nM}$ Bio-34/62Sp/36-mer, gp44/62 and gp45 (550 nM each), $1 \mu \mathrm{M}$ streptavidin, $1 \mathrm{mM}$ ATP, and $10 \mathrm{mM} \mathrm{Mg}{ }^{2+}$ or $10 \mathrm{mM} \mathrm{Mn}{ }^{2+}$ in assay buffer. The polymerization reaction was then initiated by the addition of $100 \mu \mathrm{M}$ dCTP (the next correct $\mathrm{dNTP}$ ) and an aliquot was quenched after 15 seconds (lane Inc). The remaining dNTPs (100 $\mu \mathrm{M}$ each) were added to initiate processive DNA replication. Aliquots of each reaction were quenched at the times ranging from 10300 seconds and processed as described in the text. (C) Data obtained from PhosphorImager analysis of gel electrophoresis displaying the metal-dependent differences in product accumulation upon encountering an abasic site. Product formation was quantified for the 120 second time-points depicted in (A) and (B). Product formation is denoted by the following shaded boxes: dark charcoal, 50-mer; medium charcoal, 51-mer; light charcoal, 52-mer; and white, 53-mer. As discussed in the text, the overall amount of product formation (50 to 53-mer) was greater using $\mathrm{Mg}^{2+}$ as compared to $\mathrm{Mn}^{2+}$.

$0.009( \pm 0.002) \mathrm{s}^{1}$ and $1.1( \pm 0.2) \mathrm{s}^{1}$ for the wildtype and exo replicase, respectively. It is important to note that the $k_{\text {off }}$ value of $0.009 \mathrm{~s}^{1}$ for the wildtype T4 replicase from the DNA lesion is essentially identical with that measured for the T4 replicase during precise DNA replication. However, the $k_{\text {off }}$ value for the exo replicase is increased by nearly 100 -fold at the lesion and suggests that the exo replicase becomes de-stabilized at a DNA lesion. A more detailed discussion of the mechanistic ramifications of the differences in $k_{\text {off }}$ values is provided later.

\section{Effects of perturbing DNA polymerization fidelity coupled with processivity on translesion DNA synthesis}

Our next goal was to evaluate if further perturbing fidelity coupled with decreasing the ability of the polymerase to dissociate from DNA could stimulate replication beyond the abasic lesion. To perturb fidelity further, we measured extension beyond the abasic site in the presence of $\mathrm{Mn}^{2+}$, since we demonstrated previously that substituting $\mathrm{Mn}^{2+}$ for $\mathrm{Mg}^{2+}$ alters the dynamics of translesion DNA synthesis. ${ }^{28}$ Representative data provided in Figure 5 compare directly the ability of the exo
T4 replicase in the presence of either $\mathrm{Mg}^{2+}$ or $\mathrm{Mn}^{2+}$ to extend beyond the abasic site. Full-length 62-mer product is not observed using either divalent metal ion and provides further support that increased processivity does not enhance unambiguously the ability of the $\mathrm{T} 4$ replicase to extend beyond a non-coding DNA lesion.

Despite the lack of full-length extension beyond the abasic site, it is noteworthy that substitution of $\mathrm{Mn}^{2+}$ for $\mathrm{Mg}^{2+}$ does induce a change in product distribution catalyzed by the exo replicase (compare Figure 5(A) and (B)). In the presence of $\mathrm{Mg}^{2+}$, products accumulate predominantly at positions 50 and 51, which correspond to positions prior to and opposite the abasic site, respectively. In the presence of $\mathrm{Mn}^{2+}$, products accumulate predominantly at positions 51 through 53 . These positions correspond to insertion opposite and up to two nucleobases after the abasic site. Thus, accumulation of products at these positions indicates that $\mathrm{Mn}^{2+}$ can alter the fidelity of gp43 exo since the replicase can insert dNMPs opposite and beyond the lesion. However, the lack of full-length extension suggests that the abasic site behaves as a strong block toward DNA synthesis catalyzed by the bacteriophage T4 replication system. 
A

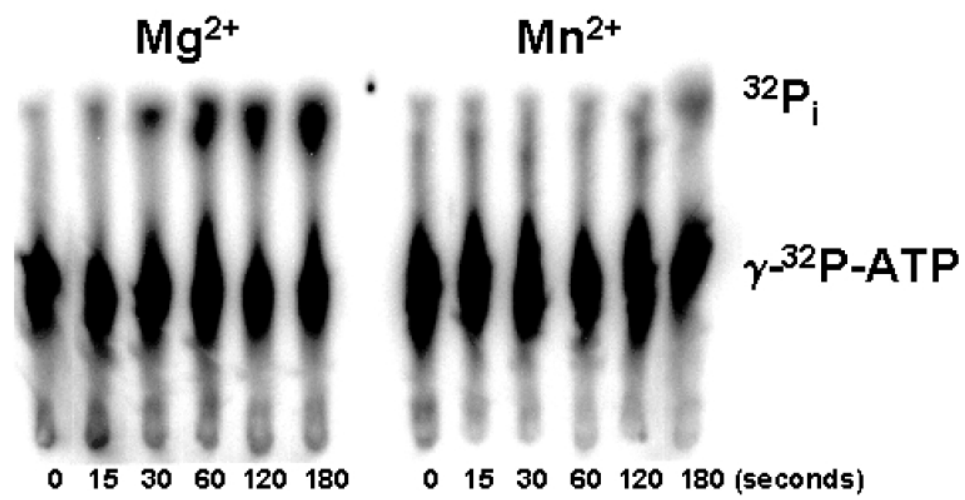

B

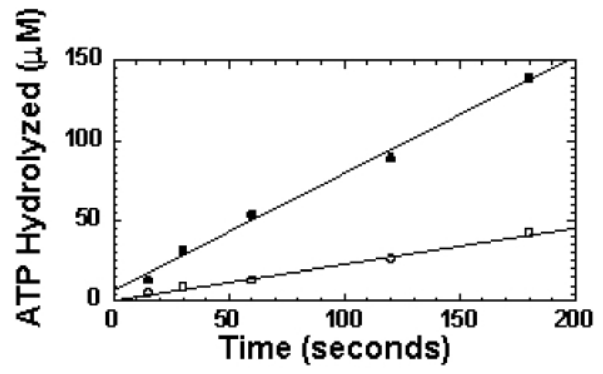

Figure 6. Substitution of $\mathrm{Mn}^{2+}$ for $\mathrm{Mg}^{2+}$ inhibits the ATPase activity of gp44/62. (A) Representative thinlayer chromatography showing the separation of ${ }^{32} \mathrm{P}_{\mathrm{i}}$ formed from the enzymatic hydrolysis of $\left[\gamma^{-32} \mathrm{P}\right]$ ATP from non-hydrolyzed $\left[\gamma^{-32} \mathrm{P}\right]$ ATP. The ATPase activity of gp44/62 was measured using $500 \mathrm{nM}$ gp44/ 62, $500 \mathrm{nM}$ gp45, $500 \mathrm{nM}$ Bio-34/ 62/36-mer, $500 \mu \mathrm{M}$ ATP, $50 \mathrm{nM}$ $\left[\gamma^{-}{ }^{32} \mathrm{P}\right] \mathrm{ATP}$, and either $10 \mathrm{mM}$ $\mathrm{MgCl}_{2}$ or $10 \mathrm{mM} \mathrm{MnCl}$ in reaction buffer. Aliquots of either reaction were quenched at the times demarcated and processed as described in the text. (B) Data obtained from PhosphorImager analysis of thinlayer chromatography displaying the gp44/62-mediated hydrolysis of $\left[\gamma^{-32} \mathrm{P}\right] \mathrm{ATP}$ in the presence of $\mathrm{Mg}^{2+}(\bullet)$ or $\mathrm{Mn}^{2+}(\bigcirc)$. The data were fit to the equation for a straight line $(y=m x+b)$ to yield steady-state rates in ATP hydrolysis of $0.73 \mu \mathrm{M} /$ second in the presence of $\mathrm{Mg}^{2+}$ and $0.19 \mu \mathrm{M} /$ second in the presence of $\mathrm{Mn}^{2+}$.

\section{Effect of $\mathrm{Mn}^{2+}$ on replicase assembly}

The metal-induced differences in product distribution were further quantified by PhosphorImaging techniques using the 120 seconds time-point as the reference. The data provided in Figure 5(C) illustrate the approximately twofold decrease in total strand displacement products using $\mathrm{Mn}^{2+}$ as opposed to $\mathrm{Mg}^{2+}$ (compare $140 \mathrm{nM}$ versus $212 \mathrm{nM}$ ). The decrease in product formation could indicate that substitution of $\mathrm{Mn}^{2+}$ for $\mathrm{Mg}^{2+}$ inhibits the DNA polymerization activity of gp43. This mechanism is unlikely, since substitution of $\mathrm{Mn}^{2+}$ for $\mathrm{Mg}^{2+}$ actually enhances the overall speed of translesion DNA synthesis (vide infra). ${ }^{27}$ An alternative possibility is that the inclusion of $\mathrm{Mn}^{2+}$ affects the activity of the accessory proteins. In this model, the decrease in polymerization reflects an inhibition of replicase assembly and/or dissociation of the replicase from the DNA lesion.

We evaluated this potential mechanism by measuring the dynamics of replicase dissociation upon encountering the abasic lesion in the presence of either $\mathrm{Mn}^{2+}$ or $\mathrm{Mg}^{2+}$. As described earlier, replicase dissociation can be quantified by measuring the increase in strand displacement products that occurs concomitantly with the depletion of the original 34-mer substrate. While this phenomenon is observed using $\mathrm{Mg}^{2+}$ as the metal cofactor, the data obtained with $\mathrm{Mn}^{2+}$ shows that the 34-mer substrate is not depleted rapidly. At face value, this result suggests that $\mathrm{Mn}^{2+}$ decreases the rate constant for replicase dissociation to enhance the processivity of the exo $\mathrm{T} 4$ replicase. The enhancement in processivity could explain the increased ability of the replicase to extend beyond the DNA lesion. Unfortunately, this mechanism cannot be evaluated unambiguously from this experiment, since the results could reflect a decrease in $k_{\text {off }}$ of the replicase (Scheme 4 , disassembly step) or a decrease in the rate of (re)assembly of the replicase once it dissociates from the lesion (Scheme 4, assembly step).

Since assembly of the T4 replicase is catalyzed by gp44/62 in a metal and ATP-dependent process, ${ }^{32}$ we hypothesized that $\mathrm{Mn}^{2+}$ might hinder this process by inhibiting the activity of gp44/62. This possibility was evaluated by measuring the rate of ATP hydrolysis by gp44/62 in the presence of stoichiometric quantities of gp45 and Bio-DNA using either $\mathrm{Mg}^{2+}$ or $\mathrm{Mn}^{2+}$ as the metal cofactor as described. ${ }^{32}$ As depicted in Figure 6(A), the amount of ATP consumed by gp44/62 during the loading of gp45 onto DNA is decreased using $\mathrm{Mn}^{2+}$ as compared to $\mathrm{Mg}^{2+}$. Further quantitative analysis yields steady-state rates in ATP consumption of $0.73 \mu \mathrm{Ms}^{1}$ in the presence of $\mathrm{Mg}^{2+}$ and $0.19 \mu \mathrm{Ms}^{1}$ in the presence of $\mathrm{Mn}^{2+}$ (Figure 6(B)). The fourfold decrease in the rate of ATP consumption by $\mathrm{Mn}^{2+}$ is consistent with a decrease in the rate of (re)assembly of the replicase complex (Scheme 4, assembly step) and potentially reflects the reason for the lower overall amount of polymerization products formed.

\section{The effect of metal ion on the fidelity of gp43}

We previously provided kinetic evidence that substitution of $\mathrm{Mn}^{2+}$ for $\mathrm{Mg}^{2+}$ enhances the ability of gp43 exo to misinsert a dNTP opposite an 

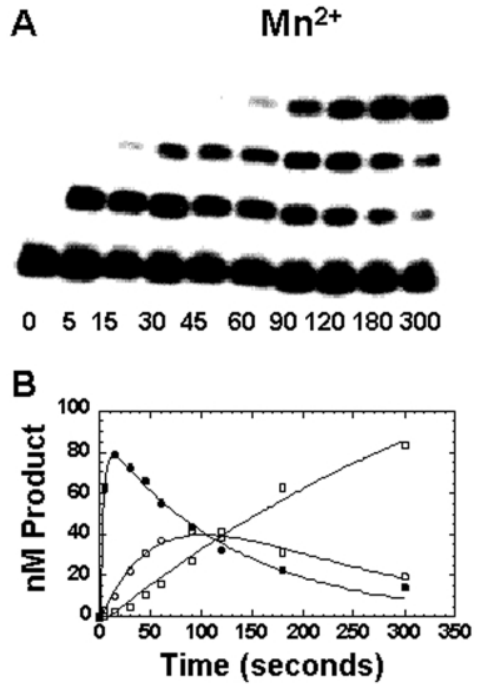
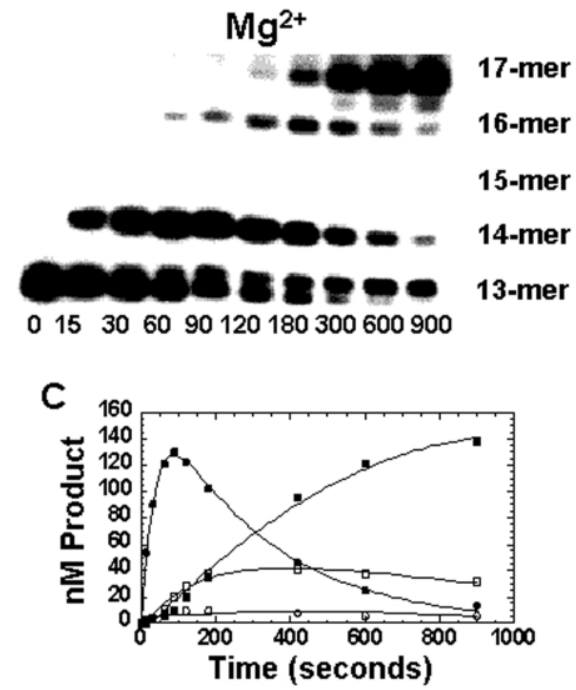

Figure 7. The effect of metal ions on the kinetics of dGTP incorporation opposite and beyond an abasic site catalyzed by the bacteriophage gp43. (A) gp43 exo $(1 \mu \mathrm{M})$ and $5^{\prime}$-labeled 13/20SP-mer $(250 \mathrm{nM})$ were preincubated with either $10 \mathrm{mM} \mathrm{Mg}^{2+}$ or $10 \mathrm{mM}$ $\mathrm{Mn}^{2+}$, mixed with dGTP to initiate the reaction, and quenched with $500 \mathrm{mM}$ EDTA at times ranging from 5900 seconds. The concentration of dGTP was $100 \mu \mathrm{M}$ using $\mathrm{Mn}^{2+}$ and $500 \mu \mathrm{M}$ using $\mathrm{Mg}^{2+}$. Because dGTP is the correct triphosphate for the next three incorporations (refer to Figure 1), a ladder of products ranging from 14 to 17 bases is observed using $\mathrm{Mg}^{2+}$ as the divalent metal ion. Despite the use of identical reaction conditions, a ladder of products ranging from 14 to 16 bases is observed using $\mathrm{Mn}^{2+}$ as the divalent metal ion. (B) The kinetics of insertion opposite and beyond an abasic site using $\mathrm{Mn}^{2+}$ as the metal cofactor. Data obtained from PhosphorImager analysis of gel electrophoresis displaying the sequential accumulation of products. Product formation is denoted as follows: $(\bullet)$ 14-mer; $(O)$ 15-mer; and $(\square)$ 16-mer. The curves for product formation were generated using the rate constants denoted in Table 1 which were obtained through computer simulation of the data. ${ }^{35}$ (C) The kinetics of insertion opposite and beyond an abasic site using $\mathrm{Mg}^{2+}$ as the metal cofactor. Data obtained from PhosphorImager analysis of gel electrophoresis displaying the sequential accumulation of products. Product formation is denoted as fol-

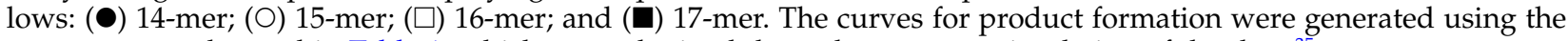
rate constants denoted in Table 1 , which were obtained through computer simulation of the data. ${ }^{35}$

abasic site. ${ }^{28}$ The data provided above additionally indicate that enhancing the processivity of gp43 exo in conjunction with $\mathrm{Mn}^{2+}$ enhances its ability to extend beyond the lesion. We further quantified the effects of $\mathrm{Mn}^{2+}$ on enhancing the ability of gp43 exo to extend beyond the abasic site using smaller defined DNA substrates (Figure 1). The use of these smaller substrates facilitated direct comparison to data previously reported using $\mathrm{Mg}^{2+} \cdot{ }^{27}$ Rates of extension were monitored under single-turnover conditions in which variable concentrations of dGTP $(5-500 \mu \mathrm{M})$ were added to a preincubated solution of $1000 \mathrm{nM}$ gp43 exo with $250 \mathrm{nM} 5^{\prime}$-labeled DNA in the presence of $10 \mathrm{mM}$ $\mathrm{Mn}^{2+}$. dGMP insertion beyond a dAMP:abasic site and a dGMP:abasic site was observed at all concentrations of dGTP tested $(5-500 \mu \mathrm{M})$, while gp43exo was unable to extend beyond a dTMP: abasic site even at the highest concentration of dGTP tested $(1 \mathrm{mM})$ (data not shown). The lack of extension beyond a pyrimidine:abasic site in the presence of $\mathrm{Mn}^{2+}$ is similar to that reported using $\mathrm{Mg}^{2+}$ as the divalent metal. ${ }^{27}$

Although the ability of gp43 exo to replicate beyond either a dAMP:abasic or a dGMP:abasic site was demonstrated with $\mathrm{Mg}^{2+},{ }^{27}$ several important differences were detected in the kinetics of extension using $\mathrm{Mn}^{2+}$. As depicted in Figure 7(A), a ladder of products ranging from 14 to 16 bases is observed in the presence of $\mathrm{Mn}^{2+}$ as opposed to the distribution of products ranging from 14 to 17 bases in the presence of $\mathrm{Mg}^{2+}$. It is interesting to note that in the presence of $\mathrm{Mn}^{2+}$, gp43 exo is able to extend only two positions beyond the aba- sic site, a distance identical with that reported above with the exo replicase in the presence of $\mathrm{Mn}^{2+}$. Despite the reduction in primer elongation, the rates corresponding to the formation of 14, 15, and 16-mers are substantially faster in the presence of $\mathrm{Mn}^{2+}$ as opposed to $\mathrm{Mg}^{2+}$ (Figure 7(B) and (C)).

To determine the rate and equilibrium constants dictating product formation, the dependency of dGTP concentration on the rates of product formation was evaluated and computer simulation was performed as described. ${ }^{27}$ Briefly, time-courses for dGMP insertion beyond the abasic site were generated, maintaining the concentration of T4 exo polymerase in a fourfold molar excess versus DNA while varying the concentration of dGTP from 10 to $500 \mu \mathrm{M}$ (data not shown). The timecourses generated provided a series of rates and stoichiometries of product formation as a function of dGTP concentration. For each concentration of dGTP, the time-course was simulated independently using $\mathrm{KinSim}^{33}$ to obtain values corresponding to $k_{\mathrm{pol}}$ and $K_{\mathrm{d}}$. Similar to data reported using $\mathrm{Mg}^{2+}, 27$ the best global fit for the dependency of dGTP concentration on extension beyond the abasic site was obtained by maintaining the $K_{\mathrm{d}}$ for dGTP fixed while varying $k_{\text {pol }}$ at each potential incorporation position. The rate and kinetic equilibrium dissociation constants summarized in Table 1 reveal that the $K_{d}$ for dGTP remains fairly constant at $50 \mu \mathrm{M}$ at each insertion position, while $k_{\text {pol }}$ values decrease successively as the primer is extended from $1.6 \mathrm{~s}^{1}$ at position $n+1$ to $0.2 \mathrm{~s}^{1}$ at position $n+3$.

The elemental effect, i.e. the effect of substituting 
Table 1. Kinetic rate and equilibrium constants for dGTP incorporation opposite and beyond an abasic site catalyzed by gp43 exo in the presence of $\mathrm{Mn}^{2+}$

\begin{tabular}{llclc}
\hline Position & $K_{\mathrm{d}}(\mu \mathrm{M})^{\mathbf{a}}$ & Fold difference $^{\mathbf{b}}$ & $k_{\text {pol }}\left(\mathrm{s}^{-1}\right)^{\mathbf{a}}$ & Fold difference $^{\mathbf{b}}$ \\
\hline $13 \rightarrow 14(n+1)$ & $50 \pm 10(200 \pm 20)^{\mathbf{c}}$ & 4 & $1.6 \pm 0.3(0.051 \pm 0.012)$ & 31 \\
$14 \rightarrow 15(n+2)$ & $50 \pm 10(200 \pm 50)$ & 4 & $0.32 \pm 0.08(0.014 \pm 0.004)$ & 23 \\
$15 \rightarrow 16(n+3)$ & $50 \pm 10(200 \pm 30)$ & 4 & $0.20 \pm 0.05(0.117 \pm 0.005)$ & 1.8 \\
\hline
\end{tabular}

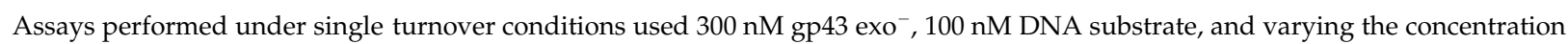
of dGTP $(10500 \mu \mathrm{M})$ in the presence of $10 \mathrm{mM} \mathrm{MnCl}_{2}$.

a Rate and equilibrium constants were obtained using computer simulation to fit the time courses in product formation as a func tion of dGTP concentration. Since single turnover reaction conditions were employed, kinetic steps reflecting enzyme dissociation and rebinding to product DNA are assumed to be negligible. Thus, the rate and amount of product formation are dependent upon two parameters, the equilibrium dissociation constant $\left(K_{\mathrm{d}}\right)$ for $\mathrm{dNTP}$ and $k_{\mathrm{pol}}$, the rate of DNA extension. $k_{\mathrm{pol}}$ was further simplified to combine the kinetic steps encompassing the conformational change prior to phosphoryl transfer, phosphoryl transfer, the confor mational change after phosphoryl transfer, and pyrophosphate release. For initial computer simulations, the $K_{d}$ value for dGTP at all potential incorporation positions was initially estimated at $50 \mu \mathrm{M}$ using the experimentally determined value for depletion of 13 mer substrate.

b Fold difference refers to the ratio of the rate or equilibrium constant measured in the presence of $\mathrm{Mn}^{2+}$ versus $\mathrm{Mg}^{2+}$.

${ }^{c}$ Values in parentheses are those previously published using $\mathrm{Mg}^{2+}$ as the divalent metal ion ${ }^{27}$ and are provided for comparison.

a non-bridging oxygen atom with a sulfur atom at the $\alpha$-phosphorus of a dNTP, was measured on the rate of extension beyond a dGMP:abasic site using a single, fixed concentration of $\alpha-S$-dGTP $(500 \mu \mathrm{M})$. Within the time-frame tested $(0-60$ seconds), extension beyond the dGMP:abasic site was not observed when $\alpha-S$-dGTP was substituted for $\alpha-O-d G T P$ (data not shown). The lack of observable extension of the 14-mer into 15-mer with $\alpha$-S-dGTP precludes accurate determination of values for $k_{\text {pol }}$. This lack of extension likewise limits our ability to measure accurately an elemental effect at this position. However, if $\alpha-S$-dGTP binds to the polymerase:DNA complex equally well as $\alpha-O-d G T P$, then the lack of extension must reflect a large elemental effect, i.e. greater than 100 .

The elemental effect on the rate of extension beyond a dAMP:abasic site was likewise measured under identical reaction conditions (data not shown). Using a single, fixed concentration of $\alpha-O-d G T P(500 \mu \mathrm{M})$, the rate constant for the conversion of 14 -mer to 15 -mer is $0.8 \mathrm{~s}^{1}$ and that measured for the conversion of 15-mer to 16-mer is $0.3 \mathrm{~s}^{1}$. Substitution of $\alpha$-S-dGTP $(500 \mu \mathrm{M})$ reduces the rate constant for the conversion of 14 -mer to 15 -mer to $0.007 \mathrm{~s}^{1}$ and provides a large elemental effect of 114. Conversion of 15-mer to 16 -mer was not observed using $\alpha$-S-dGTP within the time-frame tested $(0-15$ seconds). In this instance, the low rates of product formation cannot be interpreted unambiguously, as a thio-elemental effect since the reduction likely reflects the low levels of 15-mer production. Elemental effects are summarized in Table 2.

\section{Discussion}

Mutagenesis of the organism's genomic material is often correlated with the development of disease and/or drug-resistance. The most critical step in mutagenesis arguably occurs during DNA replication and is mediated by the ability of a
DNA polymerase to insert dNTPs opposite and beyond an unrepaired DNA lesion. Although the link between mutagenesis and dysfunctional DNA replication is obvious, the molecular details describing how polymerases initiate and propagate a mutagenic event remains poorly defined. Here, we have evaluated quantitatively the importance of several key enzymatic steps utilized by the bacteriophage T4 DNA polymerase, gp43, in the maintenance of fidelity during DNA synthesis. This was accomplished by comparing and contrasting the synthetic capabilities of gp43 alone and in concert with its processivity factor, gp45, during correct and translesion DNA replication.

Table 2. Summary of kinetic rate constants for the insertion of $\alpha$-O-dGTP or $\alpha-S$-dGTP opposite and beyond an abasic site catalyzed by gp43 exo in the presence of $\mathrm{Mn}^{2+}$

\begin{tabular}{lccc}
\hline Position & $\begin{array}{c}\alpha O \text { OGTP } \\
k_{\text {obs }}\left(\mathrm{s}^{-1}\right)^{\mathbf{b}}\end{array}$ & $\begin{array}{c}\alpha S \text { dGTP } \\
k_{\text {obs }}\left(\mathrm{s}^{-1}\right)\end{array}$ & $\begin{array}{c}\text { Elemental effect } \\
k_{\mathrm{o}} / k_{\mathrm{s}}\end{array}$ \\
\hline A. 13/20SP mer & & & \\
$13 \rightarrow 14(n+1)$ & 1.5 & 0.02 & 75 \\
$14 \rightarrow 15(n+2)$ & 0.25 & $\mathrm{ND}^{\mathrm{c}}$ & $>100^{\mathrm{d}}$ \\
$15 \rightarrow 16(n+3)$ & 0.15 & $\mathrm{ND}$ & \\
B. $14 A / 20 S P$ mer & & & 114 \\
$14 \rightarrow 15(n+2)$ & 0.8 & 0.007 & $>100$ \\
$15 \rightarrow 16(n+3)$ & 0.3 & $\mathrm{ND}$ & \\
\hline
\end{tabular}

Assays performed under single turnover conditions used $300 \mathrm{nM}$ gp $43 \mathrm{exo}^{-}, 100 \mathrm{nM}$ DNA substrate, and $500 \mu \mathrm{M}$ of either $\alpha O$ dGTP or $\alpha S$ dGTP in the presence of $10 \mathrm{mM} \mathrm{MnCl}_{2}$.

a The elemental effect on nucleotide incorporation was obtained by taking the ratio of the rate constant for incorpor ation using $\alpha O$ dGTP versus the rate constant for incorporation using $\alpha S$ dGTP.

$\mathbf{b}$ The rate constants for product formation were calculated by computer simulation of the respective time courses using the computer program $\mathrm{KinSim}^{33}$ as described in the text.

c A rate constant could not be assigned, since product for mation was not observed using $\alpha S$ dGTP.

d Since an accurate rate constant could not be assigned, the elemental effect could not be measured. Thus, an upper estimate of 100 is provided. 
The significant findings reported here include: (1) enhancing the processivity of wild-type gp43 does not enhance its ability to extend beyond a noncoding DNA lesion; (2) exonuclease proofreading does not play a major role in preventing translesion DNA synthesis, since eliminating this activity in addition to enhancing processivity does not facilitate extension beyond an abasic site; (3) the lack of exonuclease proofreading destabilizes the interaction of gp43 with gp45 upon encountering a non-coding DNA lesion; and (4) substitution of $\mathrm{Mn}^{2+}$ for $\mathrm{Mg}^{2+}$ plays a pro-mutagenic role by decreasing the fidelity of DNA synthesis catalyzed by gp43 and inhibiting the activity of the accessory proteins during replicase assembly. The justifications and ramifications of these major points are discussed in more detail below.

\section{Increasing the processivity of gp43 does not enhance the translesion DNA replication}

During leading-strand DNA replication, a variety of DNA polymerases utilize accessory proteins to increase their ability to perform processive DNA synthesis. ${ }^{10,18}$ In the case of bacteriophage T4, the intrinsically low processivity of gp43 is increased at least 200-fold through its interaction with the replicative accessory proteins that decrease the rate at which gp43 dissociates from DNA. $^{20,21}$. Although essential for proper DNA replication, increasing the processivity of gp43 by slowing its rate of dissociation from DNA could play a role in enhancing mutagenesis. As outlined in Scheme 1, preventing gp43 from dissociating from a DNA lesion (step C) may actually favor replication opposite and/or beyond the site of damage (step D) to enhance propagation of the mutagenic event.

We evaluated this mechanism quantitatively by comparing the ability of the wild-type $\mathrm{T} 4$ replicase (gp43 complexed with gp45) to perform precise versus translesion DNA replication. This comparison was performed using nearly identical DNA substrates that were either unmodified or that contained an abasic site at a defined position of the template (position 51). Using a defined and quantitative assay, 20,29 we evaluated processive DNA replication by measuring the ability of the wildtype T4 replicase to catalyze strand displacement DNA synthesis to yield fully elongated primer (production of 62-mer). Our results recapitulate previous work demonstrating that the T4 replicase is highly processive during precise DNA replication owing to the production of full-length 62-mer. ${ }^{20,21,29}$ However, upon encountering a noncoding lesion in the template strand, the wild-type T4 replicase does not extend beyond the damaged template to yield fully elongated primer. Instead, the wild-type replicase catalyzes strand displacement DNA synthesis up to the lesion and incorporates dNMPs just prior to the abasic site. The lack of translesion DNA synthesis under these conditions indicates that processivity does not compromise fidelity to enhance replication beyond a noncoding DNA lesion. Surprisingly, the exo replicase (gp43 exo complexed with gp45) is unable to fully extend beyond the DNA lesion, although it performs strand displacement DNA synthesis in a manner identical with that of the wild-type replicase. This datum indicates that the elimination of exonuclease proofreading (Scheme 1, step B) coupled with decreasing the ability of gp43 to dissociate upon encountering a DNA lesion (Scheme 1, step C) does not facilitate extension beyond the mispair to propagate a mutagenic event. By implication, the kinetic steps associated with DNA polymerization fidelity outlined in Scheme 2 must play the predominant role in preventing the initiation and propagation of genetic errors.

We note that the inability of the T4 replicase to extend beyond the abasic site could reflect the unique, non-coding nature of this class of lesion. Indeed, Reha-Krantz et al. ${ }^{34}$ demonstrated that replication beyond an $\mathrm{O}^{6}$-methylguanine adduct by gp43 required the presence of gp45, since the polymerase alone could not extend efficiently beyond this class of miscoding DNA lesion. These data, in conjunction with ours, suggest that the nature of the DNA lesion (non-coding versus miscoding) differentially affect the dynamics of replication catalyzed by the T4 DNA replicase.

\section{Does the DNA polymerase "communicate" with the processivity factor?}

The inability of either the wild-type or exo replicase to extend beyond the non-coding lesion prompted us to determine whether the replicase dissociates rapidly from the site of damage or if it remains stably bound. The "stability" of the T4 replicase was evaluated by monitoring the dynamics of its dissociation, employing the strand displacement assay in the absence of a DNA trap. Under these conditions, the observed renewal of DNA synthesis can be explained only if the replicase dissociates from the DNA lesion and then reassembles on another usable primer/template, as illustrated in Scheme 4. Since dissociation of the T4 replicase is rate-limiting for this process, the renewal of DNA synthesis provides a means to gauge its stability at the DNA lesion. In the presence of $\mathrm{Mg}^{2+}$, both wild-type and exo replicase dissociate from the abasic DNA lesion, since a renewal of DNA synthesis is observed in either case. However, the kinetics of dissociation for either replicase differ substantially, since the $k_{\text {off }}$ measured for the exo replicase is nearly 100-fold faster than that observed for the wild-type replicase $\left(1.1 \mathrm{~s}^{1}\right.$ versus $\left.0.009 \mathrm{~s}^{1}\right)$. These data indicate that the wild-type replicase is more stably associated at the site of DNA damage compared to its exo counterpart.

The relatively slow $k_{\text {off }}$ value of $0.009 \mathrm{~s}^{1}$ measured for the wild-type replicase is intriguing for several reasons. Firstly, this value is essentially 
identical with the rate constant of $0.01 \mathrm{~s}^{1}$ reported for the T4 replicase during precise DNA synthesis. ${ }^{17,20,21}$ Secondly, the identity in rate constants suggests that the dynamic interactions between polymerase and processivity are unaffected by the DNA lesion. The slow rate constant for replicase dissociation then predicts that the replicase should extend fully beyond the lesion, since the rate constants of $0.15 \mathrm{~s}^{1}$ and $\sim 0.05-$ $0.2 \mathrm{~s}^{1}$ measured for extension opposite and beyond the abasic site, respectively, are 5-20-fold faster than that for dissociation of the replicase. ${ }^{27}$ Thus, extension is predicted to be the preferred kinetic pathway. However, the inability of the replicase to extend beyond the site coupled with its long lifetime at the DNA lesion must reflect the contribution of exonuclease proofreading that excises any dNMP that is misinserted opposite the lesion.

To evaluate this hypothesis, we tested the ability of an exonuclease-deficient mutant of gp43 (in conjunction with wild-type gp45) to extend beyond the abasic DNA lesion. The removal of exonuclease proofreading coupled with enhancing processivity was predicted to facilitate translesion DNA replication, since the rate constants for extension opposite $\left(k_{\text {pol }} 0.15 \mathrm{~s}^{1}\right)$ and beyond $\left(k_{\text {pol }} \sim 0.05-0.2 \mathrm{~s}^{1}\right)$ the lesion should be faster than the predicted $k_{\text {off }}$ of $0.01 \mathrm{~s}^{1.27}$ Surprisingly, the data provided in Figure 4(B) reveals that even the exo replicase is unable to extend beyond the lesion. The lack of extension is most likely caused by the ability of the exo replicase to dissociate rapidly from the DNA lesion, i.e. $k_{\text {off }} 1.1 \mathrm{~s}{ }^{1}$. In this case, the rate constant of replicase dissociation is much faster than that for extension beyond the lesion. Thus, dissociation becomes the kinetically preferred pathway and reflects de-stabilization of the exo replicase at the site of damage.

The question still remains as to why the exo replicase would dissociate from the lesion 100-fold faster than the wild-type replicase. Sliding clamps such as gp45 and PCNA enhance the processivity of their cognate DNA polymerases by tethering it to DNA. ${ }^{12,18}$ Although distinct molecular contacts exist between the sliding clamp and polymerase, ${ }^{21,29}$ the dynamic interaction between the proteins is considered to be rather static. In other words, there appears to be little or no "communication" between the two proteins, such that the activity of gp43 does not influence the activity of gp45. One notable exception, however, has been reported during completion of an Okazaki fragment. ${ }^{35}$ In vitro studies indicate that the $k_{\text {off }}$ of the T4 replicase is enhanced 50-fold when gp43 encounters the pentameric RNA of a completed lagging strand fragment. ${ }^{35}$ These data, in conjunction with our demonstration that the $k_{\text {off }}$ of the exo replicase is increased 100 -fold during translesion DNA replication, provide kinetic evidence that gp43 can indeed communicate with gp45 to modulate the activity of processivity factor.

We have used the available three-dimensional structures of the bacteriophage $\mathrm{T} 4^{36}$ and RB69 DNA polymerases ${ }^{37-39}$ to provide insight into this potential communication mechanism. It should be noted that the high level of sequence identity $(63 \%)$ and homology (92\%) between the RB69 DNA polymerase and gp43 of bacteriophage $\mathrm{T} 4^{40}$ implies a reasonable conservation in structure between the two enzymes. Three different structures of the RB69 DNA polymerase have been described recently: one of the polymerase in the absence of DNA, ${ }^{37}$ another of the polymerase in the "editing" complex (enzyme plus nucleic acid), ${ }^{37}$ and a third of the enzyme in the "polymerization" complex (enzyme, nucleic acid, and dNTP). ${ }^{39}$ In addition, several structural models of the polymerase interacting with the sliding clamp have been reported ${ }^{37,39}$ and provide great insight into the dynamic interactions between the two proteins while bound to DNA. Comparison of these three structures provides a useful model for explaining how the enzyme partitions between polymerization and exonuclease active sites, ${ }^{39}$ an activity that undoubtedly takes place to some extent during translesion DNA replication. When switching between the two modes, the primer terminus of the nucleic acid moves a distance of $40 \AA{ }^{39}$ In addition, the helical axis of the duplex DNA is rotated $40^{\circ}$ and this rotation is required for the DNA to enter the editing mode. ${ }^{39}$ More relevant to our studies, however, is how the reported motions within the polymerase and DNA affect the interactions with the sliding clamp. Indeed, modeling of gp45 onto the polymerase: DNA complex in either the polymerization or editing mode reveals that the sliding clamp must move a substantial distance to accommodate the $40^{\circ}$ rotation of the helical axis between the two complexes. ${ }^{39}$ The net result of these motions is that the predicted interactions between gp45 and the polymerase become severely strained.

We postulate that the dynamic motions caused by shuttling the DNA between enzyme active sites affects the function of the sliding clamp and can account for the de-stabilization of the exo replicase when it encounters an abasic site. Based on the production of 51-mer as illustrated in Figure $4(\mathrm{~B})$, we propose that the lack of exonuclease proofreading first allows the replicase to misinsert a dNMP opposite the abasic lesion. Rather than extend beyond the created mispaired primer/template, gp43 partitions the DNA from the polymerase to the exonuclease active site. The reported structural data suggest that large conformational changes in both nucleic acid and gp43 must occur in order for this partitioning to occur. As a result of these dynamic movements, gp45 must also move a large distance to reorient itself with gp43 in order to maintain contact with the $C$ terminus of gp43. The inability of the exo replicase to excise the mispair may "lock" the replicase complex in this distorted position to facilitate opening $^{40}$ of the ringed-structure of gp $45^{41}$ to stimulate decomposition of the replicase complex. 
Thus, a defect in one enzymatic activity of the DNA polymerase affects the function of its accessory protein. Since the wild-type replicase is proficient in both polymerization and exonuclease proofreading, the dynamics of switching between the two active sites is left unperturbed. As a result, communication between gp43 and the sliding clamp is not affected, and the replication complex is more stable at the site of DNA damage.

This model has intriguing ramifications with regards to the dynamics of clamp dissociation. Decomposition of the $\mathrm{T} 4$ replicase is an ordered process in which release of gp45 from the C terminus of gp43 is the rate-limiting step, since the $k_{\text {off }}$ of gp $45^{20,21,30}$ is $0.01 \mathrm{~s}^{1}$ and much slower than the $k_{\text {off }}$ of $2 \mathrm{~s}^{1}$ measured for gp43 dissociation. ${ }^{15,19,20}$ We acknowledge that our current data do not allow us to determine whether gp45 is released prior to gp43 or if the two proteins dissociate simultaneously upon encountering a lesion. However, if the order of dissociation is unperturbed, then the $k_{\text {off }}$ of $\sim 1 \mathrm{~s}{ }^{1}$ measured here for the exo replicase must indicate that the off-rate for gp45 has increased 100-fold. In fact, the $k_{\text {off }}$ of the sliding clamp has increased ${ }^{20,21,30}$ from $0.01 \mathrm{~s}^{1}$ to approach the rate constant of $\sim 2 \mathrm{~s}^{1}$ normally measured for polymerase dissociation. ${ }^{15,19,20}$ The net result is that gp45 and gp43 appear to dissociate simultaneously. We are currently evaluating the dynamics of this model by independently measuring the dissociation of gp45 and gp43.

\section{The effect of manganese on replicase function}

DNA replication is a metal-dependent reaction in which $\mathrm{Mg}^{2+}$ is considered to be the physiologically relevant divalent metal ion. ${ }^{42}$ Although other divalent metal ions such as $\mathrm{Mn}^{2+}, \mathrm{Cd}^{2+}$, and $\mathrm{Ni}^{2+}$ can substitute for $\mathrm{Mg}^{2+}$, they are pro-mutagenic both in vitro and in vivo. ${ }^{43-45}$ We have demonstrated that substitution of $\mathrm{Mn}^{2+}$ for $\mathrm{Mg}^{2+}$ alters the fidelity of gp43 exo by significantly enhancing the rate of dNTP insertion opposite an abasic site. ${ }^{28}$ It was thus expected that increasing the processivity of gp43 in conjunction with reducing its fidelity with $\mathrm{Mn}^{2+}$ would lead to an even greater enhancement in the efficiency of translesion DNA replication. Surprisingly, the exo replicase was unable to fully extend beyond the abasic lesion despite the use of this promutagenic metal ion.

We note, however, that $\mathrm{Mn}^{2+}$ did alter fidelity to a certain degree, since the exo replicase could extend further beyond the abasic site than observed with $\mathrm{Mg}^{2+}$. Specifically, the exo replicase inserted opposite the abasic site and then extended two nucleobases beyond the mispair. We were compelled to evaluate the molecular reason as to why gp43 could easily initiate promutagenic errors in the presence of $\mathrm{Mn}^{2+}$ but had difficulty in fully extending beyond the lesion. Our studies switched to smaller DNA substrates (13/20-mer and 14/20mer) so that we could measure the rates of extension beyond the abasic site more accurately and quantitatively. An additional advantage is that this allowed us to compare these results directly with those published using $\mathrm{Mg}^{2+}$ as the metal ion. ${ }^{27}$ Using these smaller substrates, gp43 exo is able to extend beyond the abasic site by only two positions, a distance identical with that observed with the exo replicase in the presence of $\mathrm{Mn}^{2+}$. Although the underlying molecular mechanism accounting for this reduction is unclear, a potential explanation may involve simple destabilization of the primer-template junction via local distortion of the DNA helix. In this instance, "kinking" of the DNA may be more pronounced when the abasic site is located upstream of the primer/template junction. Indeed, steady-state ${ }^{46}$ and time-resolved fluorescent spectroscopy ${ }^{47}$ measurements reveal that 2-aminopurine undergoes a variety of dynamic conformational changes when placed opposite an abasic lesion, and that these conformational changes are dependent upon the binding of divalent cations. The data summarized in Table 2 reveal a proportional decrease in the rate constants for extension beyond either a dAMP: abasic or dGMP:abasic site as the distance from the mispair increases. Although a similar phenomenon was observed using $\mathrm{Mg}^{2+}$, ${ }^{27}$ the effect is definitely more pronounced using $\mathrm{Mn}^{2+}$ as the cofactor, especially since extension at the $n+3$ position is not observed.

While it is tempting to speculate that the reduction in $k_{\mathrm{pol}}$ values reflects alterations in the dynamics of nucleic acid structure, other potential mechanisms involving perturbations in enzymatic activity may exist. For example, it is possible that the gp43 "senses" DNA damage distal from the polymerization active site. Indeed, Gopalakrishnan \& Benkovic ${ }^{48}$ have demonstrated a spatial separation of two to three nucleobases between the polymerization and exonuclease active sites, a distance that matches very closely to the $n+2$ incorporation position where DNA replication is halted in this study. One speculation is that distortion of the DNA helix induced by the abasic site upstream of the primer/template is detected in the exonuclease active site of gp43 and inhibits extension.

Despite the reduction in primer elongation, the rates corresponding to the formation of 14,15, and 16-mers are substantially faster in the presence of $\mathrm{Mn}^{2+}$ as opposed to $\mathrm{Mg}^{2+}$ (Figure 7(B) and (C)). These data clearly support a role for $\mathrm{Mn}^{2+}$ as being a pro-mutagenic metal ion. In general, $\mathrm{Mn}^{2+}$ enhances the ability of the polymerase to perform translesion synthesis through a substantial increase in $k_{\text {pol }}$ values coupled with slight increases in binding affinity for dGTP. In fact, direct comparison to the constants obtained with $\mathrm{Mn}^{2+}$ versus $\mathrm{Mg}^{2+}$ (Table 1) indicates that $\mathrm{Mn}^{2+}$ increases the polymerization rate constant approximately 30fold for extension beyond the mispair, while lowering the binding affinity of dGTP by only fourfold. Thus, while $\mathrm{Mn}^{2+}$ may be an effective mutagen by initiating mutagenic events, i.e. dNMP misinsertion, it may not be as effective in propagating 
mutagenic events, i.e. extension beyond certain lesions such as the non-coding abasic site.

At the molecular level, it was of interest to evaluate whether $\mathrm{Mn}^{2+}$ increases $k_{\mathrm{pol}}$ by enhancing the rate of the conformational change preceding chemistry or directly enhancing the rate of phosphoryl transfer. Historically, this distinction has been addressed through the measurement of thioelemental effects on the rate constants of dNTP insertion $\dagger{ }^{49-51}$ Our studies demonstrate that in the presence of $\mathrm{Mn}^{2+}$, substitution of $\alpha-S$-dGTP for $\alpha-O$-dGTP reduces the rate of insertion opposite and beyond an abasic site significantly. In fact, the measured elemental effects of $\sim 100$ are among the highest values reported for various enzyme systems. ${ }^{52,53}$ We hesitate to interpret these large elemental effects unambiguously as an indication that phosphoryl transfer is the rate-limiting step for extension beyond the lesion. However, we can compare these large elemental effects with the lower values of between 5.6 and 10.6 reported using $\mathrm{Mg}^{2+}$ as the metal ion. ${ }^{27}$ If the large elemental effects of $\sim 100$ measured in the presence of $\mathrm{Mn}^{2+}$ truly reflects the rate-limitation on phosphoryl transfer during extension, then the rate of the conformational change prior to phosphoryl transfer must be accelerated. In conclusion, this information reflects how various metal ions influence fidelity by affecting different kinetic steps along the enzyme-catalyzed reaction pathway.

\section{Comparison with other replication systems}

Most DNA replication systems required processivity factors to stimulate the synthetic capabilities of their cognate DNA polymerases. ${ }^{10-12}$ The effect of enhanced processivity on "correct" and "incorrect" DNA synthesis has been addressed by numerous laboratories. ${ }^{54-59}$ Here, we have limited our discussion to those studies evaluating the effect of the sliding clamp on extension beyond an abasic site..$^{57-59}$ The vast majority of these studies provide kinetic evidence that increasing the processivity of the DNA polymerase through interactions with the sliding clamp facilitates extension

$\dagger$ There has been much debate regarding the utility of thio-elemental effects as a quantitative assessment of which kinetic step is rate-limiting for catalysis. ${ }^{49}{ }^{51}$ Using the Escherichia coli Klenow fragment, Mizrahi et al. ${ }^{49}$ originally observed a small elemental effect of 1.6 in the direction of polymerization and a relatively large effect of 18 in the direction of pyrophosphorolysis. This difference was attributed partially to the increase in $K_{\mathrm{eq}}$ upon replacement of $\alpha$-O-dNTP with $\alpha-S$-dNTP. ${ }^{49}$ It should be noted that in our study, the relative magnitude of the measured elemental effects is being utilized as preliminary evidence for whether phosphoryl transfer is the rate-limiting step for insertion of a dNMP opposite an abasic site. Further experimentation is clearly required to fully evaluate if the measured elemental effect reflects events associated solely with chemistry or other physical processes involving protein and/or nucleic acid. beyond an abasic site. For example, Mozzherin et al. ${ }^{57}$ reported that PCNA, the eukaryotic sliding clamp, induced a 53-fold stimulation in the ability of pol $\delta$ to extend beyond an abasic site. It has been similarly reported that the $\beta$-subunit, the sliding clamp from E. coli enhances translesion DNA synthesis with the DNA polymerase III holoenzyme. ${ }^{58,59}$ In the case of the E. coli system, however, it should be noted that the dynamics of this process appear to be dependent upon the nature of the DNA substrate. For example, Tomer \& Livneh reported that while the DNA polymerase III holoenzyme could extend beyond an abasic site when the lesion is placed within a gapped plasmid, it could not extend beyond the same lesion when it is located on a synthetic 60-mer oligonucleotide. $^{59}$ This dichotomy most likely reflects the linear versus circular nature of the DNA substrate, since the same group reported that lesion bypass was three- to fourfold slower on a linear, gapped plasmid compared to a circular gapped plasmid. ${ }^{59}$ By implication, one might argue that the inability of the bacteriophage T4 replicase to extend beyond the abasic site likewise reflects the use of linear DNA substrates. This appears unlikely, since our forked, biotinylated DNA substrate contains physical barriers at both ends of the nucleic acid that are designed to functionally mimic a circular replication fork. ${ }^{16,33} \mathrm{~A}$ more likely possibility is that our system requires the replicase to perform strand displacement DNA synthesis. The combined effects of encountering a non-coding DNA lesion during even limited strand displacement DNA synthesis may be sufficient for the termination of DNA synthesis reported here. Indeed, we have reported previously that the combined effects of strand displacement DNA synthesis upon encountering poly(A) tracts of nucleic acid facilitates the termination of DNA synthesis catalyzed by the human immunodeficiency virus I reverse transcriptase. ${ }^{60}$

\section{Conclusions and implications}

To recapitulate, we have evaluated the synthetic capabilities of gp43 alone and in concert with its processivity factor during precise and translesion DNA replication. Our data indicate that enhancing the processivity of either wild-type or an exonuclease-deficient mutant of gp43 does not enhance its ability to extend beyond an abasic site. Furthermore, our kinetic measurements provide compelling evidence that the "stability" of the replicase at a non-coding lesion is dependent upon its exonuclease proofreading capabilities. The differences in stability between the wild-type and exo replicase during translesion DNA replication have interesting ramifications with regards to potential communication between protein partners, as well as with communication of DNA replication with other biological processes such as DNA repair and recombination. The longer lifetime of the wild-type replicase in conjunction with 
its inability to insert opposite the abasic site most likely reflects the cumulative activities of polymerization and exonuclease proofreading, a process referred to as idle turnover. ${ }^{61}$ Although considered to be a futile cycle, idle turnover undoubtedly plays a role in preventing the stable insertion of a dNMP opposite a template lesion. However, another physiological ramification of idle turnover is that this process may allow the DNA polymerase to remain "stalled" at the DNA lesion to possibly sequester/localize essential repair enzymes to the site of DNA damage. In bacteriophage T4, this stalling mechanism may provide a direct link between DNA replication and DNA recombination that is essential for DNA damage avoidance. Evaluating the dynamics of this process will prove interesting with regards to recombination as well as towards mechanisms of mutagenesis and carcinogenesis.

Substitution of $\mathrm{Mn}^{2+}$ for $\mathrm{Mg}^{2+}$ plays a pro-mutagenic role by decreasing the fidelity of DNA synthesis catalyzed by gp43. However, this capacity appears limited to the initiation of the genetic errors rather than the propagation of these errors. Another interesting observation is the inhibitory effect of $\mathrm{Mn}^{2+}$ on the ATPase activity of gp44/62, the accessory protein required for efficient replicase assembly. During the process of clamp loading, $\mathrm{Mn}^{2+}$ reduces the rate of ATP consumption by nearly fourfold. Since ATP consumption is required for assembly of the $\mathrm{T} 4$ replicase, this inhibition must reflect the overall reduction in replicase re-assembly. Consistent with this mechanism is the apparent reduction in the rate of strand displacement product formation using $\mathrm{Mn}^{2+}$ as opposed to $\mathrm{Mg}^{2+}$. Thus, $\mathrm{Mn}^{2+}$ may play an unforeseen mutagenic role by affecting the activity of enzymes such as gp44/62 that are intimately involved in maintaining the continuity of the moving replication fork.

\section{Materials and Methods}

\section{Materials}

$\left[\gamma-{ }^{32} \mathrm{P}\right] \mathrm{ATP}$ and $\left[\alpha^{-32} \mathrm{P}\right] \mathrm{dCTP}$ were purchased from New England Nuclear. Unlabeled dNTPs were obtained from Pharmacia (ultrapure). ATP, $\mathrm{MgCl}_{2}, \mathrm{MnCl}_{2}$, magnesium acetate, and all buffers were from Sigma. All other materials were obtained from commercial sources and were of the highest available quality. Bacteriophage T4 polynucleotide kinase was from United States Biochemical. The T4 wild-type and exonuclease-deficient polymerase D129A (Asp219 to Ala mutation) were purified as described. ${ }^{19}$ The concentration of either polymerase was measured initially by monitoring $A_{280}$ and using an extinction coefficient of $148,000 \mathrm{M}^{1} \mathrm{~cm}^{1}$. Active-site titrations were performed as described ${ }^{19,27}$ to confirm the activity and concentration of each polymerase (Time-courses for these active-site titrations are provided as Supplementary Material, Figure S1). The T4 accessory proteins gp44/62 and gp45 were purified from overproducing strains obtained from William Konigsberg (Yale University) using protocols as described. ${ }^{62}$ The concentration of the gp44/62 and gp45 are reported as units of 4:1 complex and trimer, respectively, in agreement with the stoichiometry reported by Jarvis et al. ${ }^{31}$

\section{Nucleic acid substrates}

All oligonucleotides, including those containing a tetrahydrofuran moiety mimicking an abasic site and biotin derivatives, were synthesized by Operon Technologies (Alameda, CA). Single-stranded and duplex 13/20T and 13/20SP-mer DNA were purified and quantified as described..$^{27,63}$

The Bio-34/62/36-mer and Bio-34/62Sp/36-mer used in this study were constructed as described. ${ }^{29,30}$ Briefly, the template strand of the biotin-labeled primer/template was constructed from two shorter olignucleotides (Bio-23-mer plus 39-mer). Purified 3'-biotin labeled 23mer was $5^{\prime}$-phosphorylated by T4 polynucleotide kinase according to the manufacturer's protocol. The two template oligonucleotides were then ligated by T4 DNA ligase with the annealed primer strand (34-mer) serving to bridge the two oligonucleotides. Completion of the ligation reaction was determined by $5^{\prime}$-labelling an aliquot of the ligation reaction with $\left[\gamma^{-}{ }^{32} \mathrm{P}\right] \mathrm{ATP}$ and analyzing the sample oligonucleotide on an $8 \mathrm{M}$ urea, $90 \mathrm{mM}$ Tris, $65 \mathrm{mM}$ boric acid, $2.5 \mathrm{mM}$ EDTA ( $\mathrm{pH} \mathrm{8.3),} \mathrm{16 \%}$ $(\mathrm{w} / \mathrm{v})$ polyacrylamide sequencing gel to examine formation of the 62-mer. The duplex was then purified as described by Capson et al. ${ }^{15}$ and quantified as described by Kuchta et al. ${ }^{63}$

\section{Methods}

The assay buffer used in all kinetic studies consisted of $25 \mathrm{mM}$ Tris acetate (pH 7.5), $150 \mathrm{mM}$ potassium acetate, and $10 \mathrm{mM}$ 2-mercaptoethanol. All assays, including rapid-quench experiments using the instrument described by Johnson, ${ }^{64}$ were performed at $25^{\circ} \mathrm{C}$. Polymerization reactions were monitored by analysis of the products on either $16 \%$ or $20 \%$ polyacrylamide sequencing gels as described. ${ }^{29,63}$ Gel images were obtained with a Packard Cyclone PhosphorImager. Product formation was quantified by measuring the ratio of ${ }^{32}$ P-labelled extended and non-extended primer. The ratios of product formation are corrected for substrate in the absence of polymerase (zero point). Corrected ratios are then multiplied by the concentration of primer/template used in each assay to yield total product.

\section{Extension beyond an abasic site}

Single turnover conditions were employed when measuring the rates of extension beyond a dNMP:abasic site base-pair. A typical "bench-top" assay contained $1 \mu \mathrm{M} \mathrm{T} 4$ exo polymerase preincubated with $250 \mathrm{nM}$ DNA (13/20SP-mer) in assay buffer containing $100 \mu \mathrm{M}$ EDTA and then mixed with variable concentrations of dNTP $(0.011 \mathrm{mM})$ and $10 \mathrm{mM} \mathrm{MnCl}_{2}$. The reactions were quenched with $500 \mathrm{mM}$ EDTA at various times (5 300 seconds). Transient kinetic experiments employing the rapid-quench instrument contained $300 \mathrm{nM}$ T4 exo polymerase preincubated with $100 \mathrm{nM}$ DNA $(13 / 20 S P-m e r)$ in assay buffer containing $100 \mu \mathrm{M}$ EDTA and then mixed with variable concentrations of dNTP (0.01 $1 \mathrm{mM})$ and $10 \mathrm{mM} \mathrm{MnCl}_{2}$. The reactions were quenched with $500 \mathrm{mM}$ EDTA at various times $(0.005$ 300 seconds). Product formation using either protocol was quantified as described above. Data obtained for all 
single-turnover DNA polymerization assays were fit to equation (1) describing a single-exponential process:

$$
y=A \mathrm{e}^{k t}+C
$$

where $A$ is the burst amplitude, $k$ is the first-order rate constant, $t$ is time, and $C$ is the measured end-point in product formation.

In some instances, simulations modeling the observed kinetic time-courses for nucleotide incorporation were performed by mathematical analyses using KINSIM $^{33}$ as described. ${ }^{27}$ Both the starting reactant concentrations and rate constants were supplied for each step of the mechanism. In all cases, the rate constants were based either upon experimentally determined rate constants or published literature values. The simulated curves were then compared to those experimentally derived to judge how accurately the set of rate constants simulate the experimental data. Adjustments to the rate constants are then made until the simulated time-courses are nearly identical with the experimental time-courses. The iterative non-linear regression analysis program FITSIM was then used to predict how well the mechanism and the set of rate constants describe the experimental data.

\section{Replicase formation and processive DNA synthesis assays}

Reactions were initiated by mixing $500 \mathrm{nM}$ biotinylated primer/template, $1 \mu \mathrm{M}$ streptavidin, $100 \mu \mathrm{M}$ $\mathrm{dCTP}$, and varying concentrations of ATP in assay buffer with $200 \mathrm{nM}$ T4 exo polymerase, $550 \mathrm{nM}$ gp44/62, and $550 \mathrm{nM}$ gp45. This mixture was incubated for 15 seconds and then the remaining dNTPs $(100 \mu \mathrm{M}$ each) were added. At variable times (5 300 seconds), $10 \mu \mathrm{l}$ aliquots were quenched in $10 \mu \mathrm{l}$ of $1 \mathrm{M} \mathrm{HCl}$, extracted with $50 \mu \mathrm{l}$ of phenol/ $\mathrm{CHCl}_{3}(1: 1, \mathrm{v} / \mathrm{v})$, and then neutralized with $\sim 3 \mu \mathrm{l}$ of $3 \mathrm{M} \mathrm{NaOH}$ in $1 \mathrm{M}$ Trizma base. The polymerization products were analyzed on $16 \%$ polyacrylamide sequencing gels as described above. The amount of complex formation is equivalent to the amount of fully elongated product (62-mer) as described ${ }^{30}$

\section{Steady-state ATP hydrolysis measurements}

Assays were performed monitoring the hydrolysis of $\left[\gamma^{-}{ }^{32} \mathrm{P}\right] \mathrm{ATP}$ as described. ${ }^{32}$ Briefly, a typical assay for measuring the ATPase activity of the gp44/62 contained $500 \mathrm{nM}$ gp44/62, $500 \mathrm{nM}$ gp45, $500 \mathrm{nM}$ primer/template, $500 \mu \mathrm{M}$ ATP, $50 \mathrm{nM}\left[\gamma_{-}{ }^{32} \mathrm{P}\right] \mathrm{ATP}$, and either $10 \mathrm{mM} \mathrm{MgCl}_{2}$ or $10 \mathrm{mM} \mathrm{MnCl} \mathrm{M}_{2}$ in reaction buffer. The reactions were quenched with $1 \mathrm{M} \mathrm{HCl}$, extracted with phenol/ $\mathrm{CHCl}_{3}$ (1:1), and neutralized with $3 \mathrm{M} \mathrm{NaOH}$ in $1 \mathrm{M}$ Trizma base. The quenched samples were then analyzed by thin-layer chromatography (TLC) to separate ${ }^{32} \mathrm{P}_{\mathrm{i}}$ from non-hydrolyzed $\left[\gamma^{-32} \mathrm{P}\right]$ ATP using $0.6 \mathrm{M}$ potassium phosphate ( $\mathrm{pH}$ 3.5) as solvent. TLC images were obtained with a Packard Cyclone PhosphorImager. Product formation was quantified by measuring the ratio of ${ }^{32} \mathrm{P}_{\mathrm{i}}$ product and non-hydrolyzed $\left[\gamma^{32} \mathrm{P}\right] \mathrm{ATP}$ substrate. The ratios of product formation are corrected for substrate in the absence of enzyme (zero point). Corrected ratios are then multiplied by the final concentration of ATP $(500 \mu \mathrm{M})$ used in each assay to yield total product. Data obtained for ATP hydrolysis measurements were fit to equation (2) describing a linear function:

$$
y=A t+B
$$

where $A$ is slope value corresponding to the steady-state rate in ATP hydrolysis, $t$ is time, and $B$ is the $y$-intercept and represents the burst amplitude in ATP consumption by gp $44 / 62$.

\section{Acknowledgements}

This research was supported through funding from the Steris Foundation and the American Cancer Society (IRG-91-022-06-IRG) to the Comprehensive Cancer Center at Case Western Reserve University and University Hospitals of Cleveland.

\section{References}

1. Krohn, K. \& Paschke, R. (2002). Somatic mutations in thyroid nodular disease. Mol. Genet. Metab. 75, 202208.

2. Cleaver, J. E. \& Crowley, E. (2002). UV damage, DNA repair and skin carcinogenesis. Front. Biosci. 7, 10241043.

3. Kawanishi, S., Hiraku, Y. \& Oikawa, S. (2001). Mechanism of guanine-specific DNA damage by oxidative stress and its role in carcinogenesis and aging. Mutat. Res. 488, 6576

4. Lerma, J. G. \& Heneine, W. (2001). Resistance of human immunodeficiency virus type 1 to reverse transcriptase and protease inhibitors: genotypic and phenotypic testing. J. Clin. Virol. 21, 197212.

5. Petrosino, J., Cantu, C. \& Palzkill, T. (1998). Betalactamases: protein evolution in real time. Trends Microbiol. 6, 323327.

6. Blakley, R. L. \& Sorrentino, B. P. (1998). In vitro mutations in dihydofolate reductase that confer resistance to methotrexate: potential for clinical applications. Hum. Mutat. 11, 259263.

7. Long, M. (2001). Evolution of novel genes. Curr. Opin. Genet. Dev. 11, 673680.

8. Papavasiliou, F. N. \& Schatz, D. G. (2002). Somatic hypermutation of immunoglobulin genes: merging mechanisms for genetic diversity. Cell, 109, S35 S44.

9. Gearhart, P. J. \& Wood, R. D. (2001). Emerging links between hypermutation of antibody genes and DNA polymerases. Nature Rev. Immunol. 1, 187192.

10. Kelman, Z. \& O'Donnell, M. (1995). Structural and functional similarities of prokaryotic and eukaryotic sliding clamps. Nucl. Acids Res. 23, 36133620.

11. Young, M. C., Reddy, M. K. \& Von Hippel, P. H. (1992). Structure and function of the bacteriophage T4 DNA polymerase holoenzyme. Biochemistry, 31, 86758690

12. Sexton, D. S., Berdis, A. J. \& Benkovic, S. J. (1997). Assembly and disassembly of the DNA polymerase holoenzyme. Currr. Opin. Chem. Biol. 1, 316321.

13. Morris, C. F., Sinha, N. K. \& Alberts, B. M. (1975). Reconstitution of bacteriophage T4 DNA replication apparatus from purified components: rolling circle replication following de novo initiation on a singlestranded circular DNA template. Proc. Natl Acad. Sci. USA, 72, 48004804.

14. Nossal, N. G. (1979). DNA replication with bacteriophage T4 proteins: purification of the proteins encoded by T4 genes 41, 45, 44, and 62 using a complementation assay. J. Biol. Chem. 254, 60266031.

15. Capson, T. L., Peliska, J. A., Kaboord, B. F., Frey, 
M. W., Lively, C., Dahlberg, M. \& Benkovic, S. J. (1992). Kinetic characterization of the polymerase and exonuclease activities of the gene 43 protein of bacteriophage T4. Biochemistry, 31, 1098410994.

16. Kaboord, B. F. \& Benkovic, S. J. (1993). Rapid assembly of the bacteriophage T4 core replication complex on a linear primer/template construct. Proc. Natl Acad. Sci. USA, 90, 1088110885.

17. Sexton, D. J., Kaboord, B. F., Berdis, A. J., Carver, T. E. \& Benkovic, S. J. (1998). Dissecting the order of bacteriophage T4 DNA holoenzyme assembly. Biochemistry, 37, 77497757.

18. Kelman, Z., Hurwitz, J. \& O'Donnell, M. (1998). Processivity of DNA polymerases: two mechanisms, one goal. Curr. Biol. 6, 121125.

19. Frey, M. W., Nossal, N. G., Capson, T. L. \& Benkovic, S. J. (1993). Construction and characterization of a bacteriophage T4 DNA polymerase deficient in $3^{\prime}$ to $5^{\prime}$ exonuclease activity. Proc. Natl Acad. Sci. USA, 90, 25792583.

20. Kaboord, B. F. \& Benkovic, S. J. (1996). Dual role of the $44 / 62$ protein as a matchmaker protein and DNA polymerase chaperone during assembly of the bacteriophage T4 holoenzyme complex. Biochemistry, 35, 10841092.

21. Sexton, D. J., Carver, T. E., Berdis, A. J. \& Benkovic, S. J. (1996). Protein protein and protein DNA interactions at the bacteriophage T4 DNA replication fork. J. Biol. Chem. 271, 2804528051.

22. Loeb, L. A. (1991). Mutator phenotype may be required for multistage carcinogenesis. Cancer Res. 51, 30753079.

23. Johnson, K. A. (1993). Conformational coupling in DNA polymerase fidelity. Annu. Rev. Biochem. 62, 85713.

24. Goodman, M. F., Creighton, S., Bloom, L. B. \& Petruska, J. (1993). Biochemical basis of DNA replication fidelity. Crit. Rev. Biochem. Mol. Biol. 28, 83126.

25. Hunter, W. N., Brown, T., Anand, N. N. \& Kennard, O. (1986). Structure of an adenine cytosine base pair in DNA and its implications for mismatch repair. Nature, 320, 552555.

26. Fijalkowska, I. J., Jonczyk, P., Tkaczyk, M. M., Bialoskorska, M. \& Schaaper, R. M. (1998). Unequal fidelity of leading and lagging strand DNA replication on the Escherichia coli chromosome. Proc. Natl Acad. Sci. USA, 95, 1002010025.

27. Berdis, A. J. (2001). Dynamics of translesion DNA synthesis catalyzed by the bacteriophage T4 exonuclease-deficient DNA polymerase. Biochemistry, 40, 71807191 .

28. Hays, H. \& Berdis, A. J. (2002). Manganese substantially alters the dynamics of translesion DNA synthesis. Biochemistry, 41, 47714778.

29. Berdis, A. J., Soumillion, P. \& Benkovic, S. J. (1996). The carboxyl terminus of the bacteriophage T4 DNA polymerase is required for holoenzyme complex formation. Proc. Natl Acad. Sci. USA, 93, 1282212827.

30. Kaboord, B. F. \& Benkovic, S. J. (1995). Accessory proteins function as matchmakers in the assembly of the T4 DNA polymerase holoenzyme. Curr. Biol. 5, 149157.

31. Jarvis, T. C., Paul, L. S. \& von Hippel, P. H. (1989). Structural and enzymatic studies of the T4 DNA replication system: physical characterization of the polymerase accessory protein complex. J. Biol. Chem. 264, 1270912716.

32. Berdis, A. J. \& Benkovic, S. J. (1996). The role of ATP hydrolysis in the assembly of the bacteriophage T4
DNA replication holoenzyme complex. Biochemistry, 35, 92539265.

33. Barshop, B. A., Wren, R. F. \& Frieden, C. (1983). Analysis of numerical methods for computer simulation of kinetic processes: development of KINSIM a flexible, portable system. Anal. Biochem. 130, 134145.

34. Reha-Krantz, L. J., Nonay, R. L., Day, R. S. \& Wlison, S. H. (1996). Replication of $\mathrm{O}^{6}$-methylguanine-containing DNA by repair and replicative DNA polymerases. J. Biol. Chem. 33, 2008820095.

35. Carver, T. E., Sexton, D. J. \& Benkovic, S. J. (1997). Dissociation of bacteriophage T4 DNA polymerase and its processivity clamp after completion of Okazaki fragment synthesis. Biochemistry, 36, 1440914417.

36. Wang, J., Yu, P., Lin, T. C., Konigsberg, W. H. \& Steitz, T. A. (1996). Crystal structure of an $\mathrm{NH}_{2}$-terminal fragment of T4 DNA polymerase and its complexes with single-stranded DNA and with divalent metal ions. Biochemistry, 35, 81108119.

37. Wang, J., Sattar, A. K. M. A., Wang, C. C., Karam, J. D., Konigsberg, W. H. \& Steitz, T. A. (1997). Crystal structure of a pol $\alpha$ family replication DNA polymerase from bacteriophage RB69. Cell, 89, 10871099.

38. Shamoo, Y. \& Steitz, T. A. (1999). Building a replisome from interacting pieces: sliding clamp complexed to a peptide from DNA polymerase and a polymerase editing complex. Cell, 99, 155166.

39. Franklin, M. C., Wang, J. \& Steitz, T. A. (2001). Structure of the replicating complex of a Pol $\alpha$ family DNA polymerase. Cell, 105, 657667.

40. Karam, J. D. \& Konigsberg, W. H. (2000). DNA polymerase of the T4-related bacteriophages. Prog. Nucl. Acid Res. Mol. Biol. 64, 6596.

41. Moarefi, I., Jeruzalmi, D., Turner, J., O'Donnell, M. \& Kuriyan, J. (2000). Crystal structure of the DNA polymerase processivity factor of T4 bacteriophage. J. Mol. Biol. 296, 12151223.

42. Dawson, R. M. C., Elliott, D. C., Elliott, W. H. \& Jones, K. M. (1979). Data for Biochemical Research, 2nd edit., Clarendon Press, Oxford.

43. Beckman, R. A., Mildvan, A. S. \& Loeb, L. A. (1985). On the fidelity of DNA replication: manganese mutagenesis in vitro. Biochemistry, 24, 58105817.

44. Kasprzak, K. S., Diwan, B. A., Rice, J. M., Misra, M., Riggs, C. W., Olinski, R. \& Dizdaroglu, M. (1992). Nickel (II)-mediated oxidative DNA base damage in renal and hepatic chromatin of pregnant rats and their fetuses: possible relevance to carcinogenesis. Chem. Res. Toxicol. 5, 809815.

45. Kasprzak, K. S. (1995). Possible role of oxidative damage in metal-induced carcinogenesis. Cancer Invest. 13, 411430.

46. Stivers, J. T. (1998). 2-aminopurine fluorescence studies of base stacking interactions at abasic sites in DNA: metal ion and base sequence effects. Nucl. Acids Res. 26, 38373844.

47. Rachofsky, E. L., Seibert, E., Stivers, J. T., Osman, R. \& Ross, J. B. (2001). Conformation and dynamics of abasic sites in DNA investigated by time-resolved fluorescence of 2-aminopurine. Biochemistry, 40, 957967.

48. Gopalakrishnan, V. \& Benkovic, S. J. (1994). Spatial relationship between polymerase and exonuclease active sites of phage T4 DNA polymerase enzyme. J. Biol. Chem. 269, 2112321126.

49. Mizrahi, V., Henrie, R. N., Marlier, J. F., Johnson, K. A. \& Benkovic, S. J. (1985). Rate-limiting steps in the 
DNA polymerase I reaction pathway. Biochemistry, 24, 40104018.

50. Patel, S. S., Wong, I. \& Johnson, K. A. (1991). Presteady-state kinetic analysis of processive DNA replication including complete characterization of an exonuclease-deficient mutant. Biochemistry, 30, 511525.

51. Herschlag, D., Piccirilli, J. A. \& Cech, T. R. (1991). Ribozyme-catalyzed and nonenzymatic reactions of phosphate diesters: rate effects upon substitution of sulfur for a nonbridging phosphoryl oxygen atom. Biochemistry, 30, 48444854 .

52. Lui, J. \& Tsai, M.-D. (2001). DNA polymerase steadystate kinetic analysis of $\mathrm{dATP} \alpha \mathrm{S}$ stereoselectivity and alteration of the stereoselectivity by various metal ions and by site-directed mutagenesis. Biochemistry, 40, 90149022

53. Kravchuk, A. V., Zhao, L., Kubiak, R. J., Bruzik, K. S. \& Tsai, M.-D. (2001). Mechanism of phosphatidylinositol-specific phospholipase C: origin of unusually high nonbridging thio effects. Biochemistry, 40, 54335439 .

54. Kroutil, L. C., Frey, M. W., Kaboord, B. F., Kunkel, T. A. \& Benkovic, S. J. (1998). Effect of accessory proteins on T4 DNA polymerase replication fidelity. J. Mol. Biol. 278, 135146.

55. Chen, X., Zuo, S., Kelman, Z., O'Donnell, M., Hurwitz, J. \& Goodman, M. F. (2000). Fidelity of eucaryotic DNA polymerase $\delta$ holoenzyme from Schizosaccharomyces pombe. J. Biol. Chem. 275, 1767717682.

56. Daube, S. S., Arad, G. \& Livneh, Z. (2000). Translesion replication by DNA polymerase $\beta$ is modulated by sequence context and stimulated by fork-like structures in DNA. Biochemistry, 39, 397405.

57. Mozzherin, D. J., Shibutani, S., Tan, C.-K., Downey, K. M. \& Fisher, P. A. (1997). Proliferating cell nuclear antigen promotes DNA synthesis past template lesions by mammalian DNA polymerase $\delta$. Proc. Natl Acad. Sci. USA, 94, 61266131.

58. Pas-Elizur, T., Masaru, T., Goodman, M., O'Donnell, M. \& Livneh, Z. (1996). Mechanism of translesion
DNA synthesis by DNA polymerase II: comparison to DNA polymerases I and II core. J. Biol. Chem. 271, 2466224669.

59. Tomer, G. \& Livneh, Z. (1999). Analysis of unassisted translesion replication by the DNA polymerase III holoenzyme. Biochemistry, 38, 59485958.

60. Berdis, A. J., Stetor, S. R., LeGrice, S. F. \& Barkley, M. D. (2001). Molecular mechanism of sequence specific termination of lentiviral replication. Biochemistry, 40, 1214012149.

61. Mizrahi, V., Benkovic, P. A. \& Benkovic, S. J. (1986). Mechanism of the idling-turnover reaction of the large (Klenow) fragment of Escherichia coli DNA polymerase I. Proc. Natl Acad. Sci. USA, 83, 231235.

62. Morris, C. F., Hama-Inaba, H., Mace, D., Sinha, N. K. \& Alberts, B. (1979). Purification of the gene 43, 44, 45 , and 62 proteins of the bacteriophage T4 DNA replication apparatus. J. Biol. Chem. 254, 67876796.

63. Kuchta, R. D., Benkovic, P. A. \& Benkovic, S. J. (1988). Kinetic mechanism whereby DNA polymerase I (Klenow) replicates with high fidelity. Biochemistry, 27, 67166725 .

64. Johnson, K. A. (1995). Rapid quench kinetic analysis of polymerases, adenosinetriphosphatases, and enzyme intermediates. Methods Enzymol. 249, 3861. 